\title{
Article \\ Co-Occurrence of 35 Mycotoxins: A Seven-Year Survey of Corn Grain and Corn Silage in the United States
}

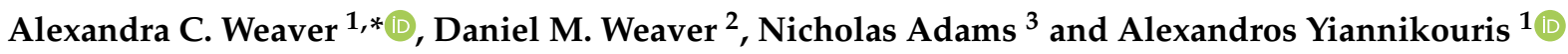 \\ 1 Alltech Inc., 3031 Catnip Hill Road, Nicholasville, KY 40356, USA; ayiannikouris@alltech.com \\ 2 Independent Researcher, Orrington, ME 04474, USA; dmw1121@gmail.com \\ 3 Alltech UK, Stamford PE9 1TZ, UK; nadams@alltech.com \\ * Correspondence: aweaver@alltech.com
}

check for

updates

Citation: Weaver, A.C.; Weaver, D.M.; Adams, N.; Yiannikouris, A. Co-Occurrence of 35 Mycotoxins: A Seven-Year Survey of Corn Grain and Corn Silage in the United States. Toxins 2021, 13, 516. https://doi.org/ $10.3390 /$ toxins 13080516

Received: 1 July 2021

Accepted: 20 July 2021

Published: 23 July 2021

Publisher's Note: MDPI stays neutral with regard to jurisdictional claims in published maps and institutional affiliations.

Copyright: (c) 2021 by the authors. Licensee MDPI, Basel, Switzerland. This article is an open access article distributed under the terms and conditions of the Creative Commons Attribution (CC BY) license (https:// creativecommons.org/licenses/by/ $4.0 /)$.
Abstract: Mycotoxins contaminate crops worldwide and play a role in animal health and performance. Multiple mycotoxins may co-occur which may increase the impact on the animal. To assess the multiple mycotoxin profile of corn (Zea mays), we conducted a 7-year survey of new crop corn grain and silage in the United States. A total of 711 grain and 1117 silage samples were collected between 2013 and 2019 and analyzed for the simultaneous presence of 35 mycotoxins using ultra-performance liquid chromatography-tandem mass spectrometry. The measured mean number of mycotoxins per sample were 4.8 (grain) and 5.2 (silage), ranging from 0 to 13. Fusaric acid (FA) was most frequently detected in 78.1 and $93.8 \%$ of grains and silages, respectively, followed by deoxynivalenol (DON) in 75.7 and $88.2 \%$ of samples. Fumonisin B1 (FB1), fumonisin B2 and 15-acetyl-deoxynivalenol $(15 \mathrm{ADON})$ followed. The greatest $(p<0.05)$ co-occurrence was between FA and DON in $59.1 \%$ of grains and $82.7 \%$ of silages, followed by FA with FB1, DON with 15ADON, and FA with 15ADON. Although many samples had lower mycotoxin concentrations, $1.6 \%$ (grain) and $7.9 \%$ (silage) of tested samples had DON $\geq 5000 \mu \mathrm{g} / \mathrm{kg}$. Fumonisins were detected $\geq 10,000 \mu \mathrm{g} / \mathrm{kg}$ in 9.6 and $3.9 \%$ of grain and silage samples, respectively. Concentrations in grain varied by year for eight mycotoxin groups $(p<0.05)$, while all 10 groups showed yearly variations in silage. Our survey suggest that multiple mycotoxins frequently co-occur in corn grain and silage in the United States, and some of the more prevalent mycotoxins are those that may not be routinely analyzed (i.e., FA and 15ADON). Assessment of multiple mycotoxins should be considered when developing management programs.

Keywords: co-occurrence; corn; deoxynivalenol; fusaric acid; Fusarium; monitoring; maize; mycotoxins; silage

Key Contribution: Mycotoxins contaminate corn grain and silage, with frequent co-occurrence of FA with DON, FA with 15ADON and FA with FB1, highlighting the importance of assessing multiple mycotoxins, including emerging mycotoxins and mycotoxin metabolites, when developing risk management programs.

\section{Introduction}

In the United States, corn (Zea mays) is an important grain and forage crop and is used as the primary energy ingredient in livestock feed. As a cereal, corn is subject to infection by numerous diseases including fungal diseases of the Aspergillus, Fusarium and Penicillium genera [1]. Colonization and growth of these fungi can lead to a variety of impacts on the crop, such as reduced yield and altered quality, as well as mycotoxin contamination [2] Mycotoxins, or secondary metabolites produced by molds, are particularly problematic for livestock production due to capability of these compounds to modulate metabolism and microbial response including adverse effects on intestinal and immune health, reproduction, gain and efficiency [3].

The growth of molds and the production of mycotoxins is influenced by a variety of factors including climatic conditions, agronomic practices and physical handling of grains 
and plant material [4]. Furthermore, mycotoxins can be produced at all steps of crop and feed production, i.e., before harvest, at harvest, during feedstuff storage, throughout feed processing, during storage of complete feeds or at feed out on-farm. If mycotoxins are formed at any of these steps, decreasing their contamination levels by chemical, biochemical or physical means is difficult due to their inherent stability to temperature, $\mathrm{pH}[3,4]$ or other biotic detoxification approaches. Therefore, livestock are likely to consume mycotoxins which could lead to negative effects on health and performance.

Although global mycotoxin regulations tend to focus on a few key mycotoxins individually, there are many different types of mycotoxins including conjugated and emerging mycotoxins [5,6]. Additionally, crops are rarely contaminated with one mycotoxin but rather numerous mycotoxins simultaneously. A recent survey of corn silage from Flanders, Belgium indicated that $47 \%$ of samples contained five or more mycotoxins out of the 22 analyzed [5]. As animals are chronically exposed to mixtures of mycotoxins during their entire lifecycle, even lower concentrations may result in interactions that impact health, production, and efficiency [7]. Therefore, assessing the presence of multiple mycotoxins in feedstuffs and finished rations is of importance, even when those mycotoxins may be below regulatory limits.

In the past decade, numerous surveys have been published from around the world showing mycotoxin contamination profiles. However, few have focused on North American corn production, with even fewer investigating mycotoxin profiles in both corn grain and whole plant corn silage. Thus, the aim of this research was to investigate mycotoxin profiles in corn grain and corn silage harvested in the United States of America over a 7-year period from 2013 to 2019. Furthermore, all samples in this study were analyzed for 35 individual mycotoxins that included isomers, conjugated and emerging mycotoxins, to track the occurrence of multiple mycotoxins in these commodities over time and without decision bias.

\section{Results}

\subsection{Mycotoxin Concentrations and Occurrence \\ 2.1.1. Corn Grain}

Measurable concentrations of mycotoxins were detected in $98.6 \%$ of corn grain samples with $90.2 \%$ of samples containing two or more mycotoxins (Table 1 ). The mean number of mycotoxins per sample was $4.79 \pm 2.44$ with a minimum of 0 and a maximum of 12 mycotoxins detected in these samples out of the 35 tested. Only $1.4 \%$ of samples did not contain mycotoxins. The most prevalent mycotoxin group was the type $\mathrm{B}$ trichothecenes comprising deoxynivalenol (DON), 3-acetyl-deoxynivalenol (3ADON), 15-acetyl-deoxynvalenol (15ADON), deoxynivalenol-3-glucoside (D3G), nivalenol (NIV) and fusarenon X (FX), detected in $81.7 \%$ of samples (Table 2). The emerging mycotoxins, composed of fusaric acid (FA) and alternariol, closely followed in $78.1 \%$ of grain samples, total fumonisins (FBs) which includes fumonisin B1 (FB1), fumonisin B2 (FB2) and fumonisin B3 (FB3) were in $69.3 \%$ of samples, and zearalenone (ZEA) was detected in $21.2 \%$ of samples. Type A trichothecenes, composed of T-2 toxin (T2), HT-2 toxin (HT2), diacetoxyscirpenol and neosolaniol, was detected in $13.2 \%$ of samples. All other mycotoxin groups were detected, but in less than $10 \%$ of samples.

The most prevalent individual mycotoxin was FA in $78.1 \%$ of samples, with a mean concentration of $207 \pm 460 \mu \mathrm{g} / \mathrm{kg}$ and median of $88.7 \mu \mathrm{g} / \mathrm{kg}$ (Table 3). Although the maximum detected level of FA was $6792 \mu \mathrm{g} / \mathrm{kg}$, $75 \%$ of positive samples had concentrations less than $205 \mu \mathrm{g} / \mathrm{kg}$. Deoxynivalenol was the second most prevalent mycotoxin in $75.7 \%$ of samples. The mean for DON was $840 \pm 1790 \mu \mathrm{g} / \mathrm{kg}$, the median $333 \mu \mathrm{g} / \mathrm{kg}$ and maximum $27,000 \mu \mathrm{g} / \mathrm{kg}$, with the upper $25 \%$ of positive samples having concentrations of DON above $914 \mu \mathrm{g} / \mathrm{kg}$. Other prevalent mycotoxins included FB1 in 65.7\%, FB2 in 53.4\%, 15ADON in $47.7 \%$ and FB3 in $41.8 \%$ of samples. Fumonisin B1 was detected in corn grain at an average value of $3800 \pm 6100 \mu \mathrm{g} / \mathrm{kg}$ (median $1340 \mu \mathrm{g} / \mathrm{kg}$; maximum 52,500 $\mu \mathrm{g} / \mathrm{kg}$ ) with $75 \%$ of positive samples having concentrations less than $4750 \mu \mathrm{g} / \mathrm{kg}$. Fumonisin B2 and FB3, had 
means of $738 \pm 1150$ and $462 \pm 651 \mu \mathrm{g} / \mathrm{kg}$ (medians 204 and $162 \mu \mathrm{g} / \mathrm{kg}$; maximums 5640 and $2800 \mu \mathrm{g} / \mathrm{kg}$ ) with $75 \%$ percentiles of 772 and $554 \mu \mathrm{g} / \mathrm{kg}$, respectively. The mean of $15 \mathrm{ADON}$ was $91.6 \pm 137 \mu \mathrm{g} / \mathrm{kg}$, median $52.1 \mu \mathrm{g} / \mathrm{kg}$ and maximum $1170 \mu \mathrm{g} / \mathrm{kg}$, with $75 \%$ quartile of $96.5 \mu \mathrm{g} / \mathrm{kg}$. Of additional importance was the presence of ZEA in $21.2 \%$ of samples. Zearalenone was found at an average of $302 \pm 486 \mu \mathrm{g} / \mathrm{kg}$, median $115 \mu \mathrm{g} / \mathrm{kg}$ and maximum $2890 \mu \mathrm{g} / \mathrm{kg}$. Interestingly, the top $25 \%$ of positive samples had concentrations greater than $337 \mu \mathrm{g} / \mathrm{kg}$. In corn grain, all other measured mycotoxins were detected in less than $20 \%$ of samples. Only NIV and ergocryptine were not detected in the 711 corn grain samples analyzed.

Table 1. Distribution of the number of mycotoxins detected and their proportion in all samples of corn grain and silage.

\begin{tabular}{ccccc}
\hline & \multicolumn{2}{c}{ Corn Grain } & \multicolumn{2}{c}{ Corn Silage } \\
\cline { 2 - 5 } $\begin{array}{c}\text { Number of } \\
\text { Mycotoxins }\end{array}$ & $\begin{array}{c}\text { Number of } \\
\text { Samples }\end{array}$ & Proportion (\%) & $\begin{array}{c}\text { Number of } \\
\text { Samples }\end{array}$ & Proportion (\%) \\
\hline 0 & 10 & 1.4 & 5 & 0.4 \\
1 & 60 & 8.4 & 31 & 2.8 \\
$2-3$ & 161 & 22.6 & 233 & 49.9 \\
$4-6$ & 306 & 43.0 & 547 & 23.5 \\
$7-9$ & 150 & 21.1 & 263 & 3.2 \\
$10-12$ & 24 & 3.4 & 36 & 0.2 \\
13 or more & 0 & 0.0 & 2 & \\
Mean \pm SD & $4.79 \pm 2.44$ & & $5.18 \pm 2.26$ & \\
Minimum & 0 & & 0 & 13 \\
Maximum & 12 & &
\end{tabular}

Table 2. Occurrence, mean (SD), median, $25 \%$ and $75 \%$ quartiles, and maximum concentrations ( $\mu \mathrm{g} / \mathrm{kg}$ ) of mycotoxin positive samples by mycotoxin groups in corn grain $(n=711)$.

\begin{tabular}{|c|c|c|c|c|c|c|c|}
\hline \multirow[b]{2}{*}{ Mycotoxin Groups ${ }^{1}$} & \multicolumn{2}{|c|}{ Samples } & \multicolumn{5}{|c|}{ Concentrations $(\mu \mathrm{g} / \mathrm{kg})$} \\
\hline & Number & $\%$ & Mean \pm SD & Median & 25\% Quartile & 75\% Quartile & Maximum \\
\hline Aflatoxin B1 & 12 & 1.7 & $58.1(173)$ & 7.1 & 4.5 & 14.6 & 606 \\
\hline Aflatoxins, total & 54 & 7.6 & $15.2(82.8)$ & 2.7 & 2.0 & 4.6 & 611 \\
\hline Ochratoxins & 48 & 6.8 & $4.9(2.4)$ & 5.5 & 2.2 & 6.4 & 11.6 \\
\hline Type B trichothecenes & 581 & 81.7 & $900(2020)$ & 332 & 117 & 965 & 33,230 \\
\hline Type A trichothecenes & 94 & 13.2 & $40.6(71.8)$ & 19.7 & 7.2 & 40.5 & 618 \\
\hline Fumonisins & 493 & 69.3 & $4446(7360)$ & 1361 & 333 & 5333 & 59,117 \\
\hline Zearalenone & 151 & 21.2 & $301(486)$ & 115 & 43.8 & 337 & 2894 \\
\hline Emerging mycotoxins & 555 & 78.1 & $207(460)$ & 89.3 & 31.4 & 205 & 6792 \\
\hline Penicillium mycotoxins & 65 & 9.1 & $166(341)$ & 13.6 & 5.2 & 134 & 1688 \\
\hline Aspergillus mycotoxins & 44 & 6.2 & $50.9(143)$ & 4.2 & 3.8 & 9.5 & 608 \\
\hline Ergot alkaloids & 23 & 3.2 & $4.0(2.6)$ & 3.5 & 1.7 & 5.5 & 10.2 \\
\hline
\end{tabular}

${ }^{1}$ Aflatoxins, total: aflatoxin B1 + aflatoxin B2 + aflatoxin G1 + aflatoxin G2; ochratoxins: ochratoxin A + ochratoxin B; type B trichothecenes: deoxynivalenol + 3-acetyl-deoxynivalenol + 15-acetyl-deoxynvalenol + deoxynivalenol-3-glucoside + nivalenol + fusarenon $\mathrm{X}$; type A trichothecenes: T-2 toxin + HT-2 toxin + diacetoxyscirpenol + neosolaniol; fumonisins: fumonisin B1 + fumonisin B2 + fumonisin B3; emerging mycotoxins: fusaric acid + alternariol; Penicillium mycotoxins: patulin + mycophenolic acid + roquefortine $\mathrm{C}+$ penicillic acid; Aspergillus mycotoxins: wortmannin + gliotoxin + sterigmatocystin + verruculogen; ergot alkaloids: ergometrine + ergotamine + ergocryptine + lysergol + methylergonovine. 
Table 3. Occurrence, mean (SD), median, $25 \%$ and $75 \%$ quartiles, and maximum concentrations ( $\mu \mathrm{g} / \mathrm{kg}$ ) of positive samples for individual mycotoxins in corn grain $(n=711)$.

\begin{tabular}{|c|c|c|c|c|c|c|c|}
\hline \multirow[b]{2}{*}{ Mycotoxins } & \multicolumn{2}{|c|}{ Samples } & \multicolumn{5}{|c|}{ Concentrations $(\mu \mathrm{g} / \mathrm{kg})$} \\
\hline & Number & $\%$ & Mean (SD) & Median & 25\% Quartile & 75\% Quartile & Maximum \\
\hline Aflatoxin B1 & 12 & 1.7 & $58.1(173)$ & 7.1 & 4.5 & 14.6 & 606 \\
\hline Aflatoxin B2 & 16 & 2.3 & $3.6(1.2)$ & 3.2 & 2.7 & 4.5 & 5.9 \\
\hline Aflatoxin G1 & 3 & 0.4 & $2.9(3.1)$ & 1.3 & 1.1 & 3.8 & 6.4 \\
\hline Aflatoxin G2 & 28 & 3.9 & $2.0(0.5)$ & 2.0 & 1.7 & 2.2 & 3.1 \\
\hline Ochratoxin A & 32 & 4.5 & $5.5(1.5)$ & 6.0 & 5.3 & 6.5 & 7.0 \\
\hline Ochratoxin B & 19 & 2.7 & $3.1(2.0)$ & 2.2 & 2.0 & 3.3 & 9.7 \\
\hline Deoxynivalenol & 538 & 75.7 & $840(1790)$ & 333 & 129.2 & 914 & 26,974 \\
\hline $3 \mathrm{ADON}^{1}$ & 100 & 14.1 & $32.1(50.3)$ & 17.1 & 10.7 & 30.3 & 408 \\
\hline $15 \mathrm{ADON}^{1}$ & 339 & 47.7 & $91.6(137)$ & 52.1 & 25.2 & 96.5 & 1172 \\
\hline $\mathrm{D}_{3} \mathrm{G}^{1}$ & 138 & 19.4 & $218(454)$ & 124 & 72.0 & 213 & 5084 \\
\hline Nivalenol & 0 & 0 & - & - & - & - & - \\
\hline Fusarenon $X$ & 51 & 7.2 & $130(477)$ & 23.4 & 17.1 & 43.0 & 3204 \\
\hline $\mathrm{T}-2$ toxin & 53 & 7.5 & $18.7(32.0)$ & 9.6 & 6.6 & 17.5 & 227 \\
\hline HT-2 toxin & 42 & 5.9 & $58.3(63.9)$ & 37.9 & 19.9 & 81.6 & 364 \\
\hline Diacetoxyscirpenol & 13 & 1.8 & $10.7(6.4)$ & 7.6 & 6.1 & 15.4 & 24.1 \\
\hline Neosolaniol & 15 & 2.1 & $15.4(12.4)$ & 13.8 & 5.7 & 23.9 & 45.5 \\
\hline Fumonisin B1 & 467 & 65.7 & $3800(6100)$ & 1340 & 390 & 4750 & 52,503 \\
\hline Fumonisin B2 & 380 & 53.4 & $738(1150)$ & 204 & 62.3 & 772 & 5643 \\
\hline Fumonisin B3 & 297 & 41.8 & $462(651)$ & 162 & 46.4 & 554 & 2802 \\
\hline Zearalenone & 151 & 21.2 & $302(486)$ & 115 & 43.8 & 337 & 2894 \\
\hline Fusaric acid & 555 & 78.1 & $207(460)$ & 88.7 & 31.4 & 205 & 6792 \\
\hline Alternariol & 2 & 0.3 & $69.4(31.1)$ & 69.4 & 58.4 & 80.4 & 91.4 \\
\hline Patulin & 2 & 0.3 & $106(41.9)$ & 106 & 91.6 & 121 & 136.0 \\
\hline Mycophenolic acid & 44 & 6.2 & $202(391)$ & 17.1 & 5.5 & 190 & 1688 \\
\hline Roquefortine C & 16 & 2.3 & $4.6(2.8)$ & 5.1 & 2.4 & 5.5 & 11.6 \\
\hline Penicillic acid & 6 & 0.8 & 195 (193) & 127 & 43.1 & 315 & 493 \\
\hline Wortmannin & 3 & 0.4 & $150(157)$ & 129 & 66.7 & 222 & 315 \\
\hline Gliotoxin & 6 & 0.8 & $340(245)$ & 423 & 124 & 498 & 608 \\
\hline Sterigmatocystin & 33 & 4.6 & $4.0(1.0)$ & 3.8 & 3.5 & 5.1 & 5.3 \\
\hline Verruculogen & 15 & 2.1 & $4.5(0.8)$ & 4.7 & 4.4 & 4.9 & 5.9 \\
\hline Ergometrine & 1 & 0.1 & $3.8(0)$ & 3.8 & 3.8 & 3.8 & 3.8 \\
\hline Ergotamine & 12 & 1.7 & $4.2(2.3)$ & 3.5 & 2.6 & 5.2 & 10.2 \\
\hline Ergocryptine & 0 & 0 & - & - & - & - & - \\
\hline Lysergol & 3 & 0.4 & $4.1(3.5)$ & 2.7 & 2.1 & 5.4 & 8.1 \\
\hline Methylergonovine & 11 & 1.5 & $2.3(1.4)$ & 1.7 & 1.5 & 3.1 & 4.6 \\
\hline
\end{tabular}

${ }^{1}$ 3ADON: 3-acetyl-deoxynivalenol; 15ADON: 15-acetyl-deoxynvalenol; D3G: deoxynivalenol-3-glucoside.

\subsubsection{Corn Silage}

Mycotoxins were detected in $99.6 \%$ of corn silage samples, with $96.8 \%$ of samples containing two or more mycotoxins (Table 1). Samples contained from 0 to 13 mycotoxins at a time, with the mean number of mycotoxins per sample at $5.18 \pm 2.26$. Only $0.4 \%$ of samples did not contain mycotoxins. The most prevalent mycotoxin group in corn silage was the emerging mycotoxins found in $93.8 \%$ of samples, with type B trichothecenes also in a high percentage of samples at $89.5 \%$ (Table 4 ). Fumonisins were detected in $67.3 \%$ of samples. Total aflatoxins (AFs; aflatoxin B1 (AFB1), aflatoxin B2, aflatoxin G1, aflatoxin G2), type A trichothecenes, ZEA, Penicillium mycotoxins and ergot toxins were all detected at similar rates of $21.2 \%, 28.9 \%, 17.8 \%, 16.1 \%$ and $20.2 \%$, respectively. The other mycotoxin groups were detected in less than $10 \%$ of samples. 
Table 4. Occurrence, mean (SD), median, $25 \%$ and $75 \%$ quartiles, and maximum concentrations ( $\mu \mathrm{g} / \mathrm{kg}$ ) of mycotoxin positive samples by mycotoxin groups in corn silage $(n=1117)$.

\begin{tabular}{|c|c|c|c|c|c|c|c|}
\hline \multirow[b]{2}{*}{ Mycotoxin Groups ${ }^{1}$} & \multicolumn{2}{|c|}{ Samples } & \multicolumn{5}{|c|}{ Concentrations $(\mu \mathrm{g} / \mathrm{kg})$} \\
\hline & Number & $\%$ & Mean \pm SD & Median & 25\% Quartile & 75\% Quartile & Maximum \\
\hline Aflatoxin B1 & 88 & 7.9 & $9.5(13.0)$ & 4.6 & 2.2 & 11.5 & 82.4 \\
\hline Aflatoxins, total & 237 & 21.2 & $18.0(37)$ & 7.1 & 2.9 & 22.8 & 423 \\
\hline Ochratoxins & 24 & 2.1 & $9.7(15.9)$ & 4.9 & 2.2 & 9.5 & 76.3 \\
\hline Type B trichothecenes & 1000 & 89.5 & $2169(2900)$ & 1090 & 456 & 2650 & 19,849 \\
\hline Type A trichothecenes & 323 & 28.9 & $181(459)$ & 40.8 & 17.6 & 130 & 3712 \\
\hline Fumonisins & 752 & 67.3 & $2227(5100)$ & 449 & 152 & 1665 & 53,046 \\
\hline Zearalenone & 199 & 17.8 & $560(683)$ & 304 & 77.4 & 781 & 4021 \\
\hline Emerging mycotoxins & 1048 & 93.8 & $661(805)$ & 361 & 152 & 840 & 5195 \\
\hline Penicillium mycotoxins & 180 & 16.1 & $151(216)$ & 88.9 & 19.6 & 183 & 1411 \\
\hline Aspergillus mycotoxins & 65 & 5.8 & $128(241)$ & 37.2 & 3.4 & 135 & 1232 \\
\hline Ergot alkaloids & 226 & 20.2 & $16.5(64.4)$ & 3.2 & 1.7 & 9.0 & 811 \\
\hline
\end{tabular}

${ }^{1}$ Aflatoxins, total: aflatoxin B1 + aflatoxin B2 + aflatoxin G1 + aflatoxin G2; ochratoxins: ochratoxin A + ochratoxin B; type B trichothecenes: deoxynivalenol + 3-acetyl-deoxynivalenol + 15-acetyl-deoxynvalenol + deoxynivalenol-3-glucoside + nivalenol + fusarenon $\mathrm{X}$; type $\mathrm{A}$ trichothecenes: T-2 toxin + HT-2 toxin + diacetoxyscirpenol + neosolaniol; fumonisins: fumonisin B1 + fumonisin B2 + fumonisin B3; emerging mycotoxins: fusaric acid + alternariol; Penicillium mycotoxins: patulin + mycophenolic acid + roquefortine $\mathrm{C}+$ penicillic acid; Aspergillus mycotoxins: wortmannin + gliotoxin + sterigmatocystin + verruculogen; ergot alkaloids: ergometrine + ergotamine + ergocryptine + lysergol + methylergonovine.

All 35 measured mycotoxins were detected in corn silage samples (Table 5). Prevalence rates of individual mycotoxins followed a similar trend to corn grain, with the most prevalent mycotoxin being FA (93.8\%) followed by DON (88.2\%). The average concentration of FA in corn silage samples was $660 \pm 805 \mu \mathrm{g} / \mathrm{kg}$, with a median value of $361 \mu \mathrm{g} / \mathrm{kg}$, a maximum of $5190 \mu \mathrm{g} / \mathrm{kg}$ and $75 \%$ of positive samples having concentrations less than $838 \mu \mathrm{g} / \mathrm{kg}$. Deoxynivalenol was detected at a mean of $1870 \pm 2440 \mu \mathrm{g} / \mathrm{kg}$, median of $968 \mu \mathrm{g} / \mathrm{kg}$ and maximum of $16,603 \mu \mathrm{g} / \mathrm{kg}$. The top $25 \%$ of samples had DON concentrations greater than $2189 \mu \mathrm{g} / \mathrm{kg}$.

Table 5. Occurrence, mean (SD), median, $25 \%$ and $75 \%$ quartiles, and maximum concentrations ( $\mu \mathrm{g} / \mathrm{kg}$ ) of positive samples for individual mycotoxins in corn silage $(n=1117)$.

\begin{tabular}{|c|c|c|c|c|c|c|c|}
\hline \multirow[b]{2}{*}{ Mycotoxins } & \multicolumn{2}{|c|}{ Samples } & \multicolumn{5}{|c|}{ Concentrations $(\mu \mathrm{g} / \mathrm{kg})$} \\
\hline & Number & $\%$ & Mean (SD) & Median & 25\% Quartile & 75\% Quartile & Maximum \\
\hline Aflatoxin B1 & 88 & 7.9 & $9.5(13.0)$ & 4.6 & 2.2 & 11.5 & 82.4 \\
\hline Aflatoxin B2 & 70 & 6.3 & $15.6(19.9)$ & 6.1 & 3.0 & 22.8 & 97.1 \\
\hline Aflatoxin G1 & 39 & 3.5 & $3.1(2.8)$ & 1.8 & 1.1 & 4.9 & 9.8 \\
\hline Aflatoxin G2 & 66 & 5.9 & $33.5(61.5)$ & 21.0 & 11.6 & 31.2 & 423 \\
\hline Ochratoxin A & 18 & 1.6 & $6.5(8.1)$ & 4.2 & 2.2 & 7.2 & 36.7 \\
\hline Ochratoxin B & 6 & 0.5 & $19.3(28.1)$ & 9.6 & 6.5 & 11.6 & 76.3 \\
\hline Deoxynivalenol & 985 & 88.2 & $1870(2440)$ & 968 & 413 & 2189 & 16,603 \\
\hline $3 \mathrm{ADON}^{1}$ & 214 & 19.2 & $116(223)$ & 52.4 & 24.8 & 114 & 2109 \\
\hline $15 \mathrm{ADON}^{1}$ & 437 & 39.1 & $594(684)$ & 342 & 177 & 714 & 3813 \\
\hline $\mathrm{D}_{3} \mathrm{G}^{1}$ & 84 & 7.5 & $211(313)$ & 100 & 54.1 & 246 & 2202 \\
\hline Nivalenol & 7 & 0.6 & $388(338)$ & 239 & 203 & 374 & 1130 \\
\hline Fusarenon $\mathrm{X}$ & 40 & 3.6 & $635(644)$ & 408 & 188 & 920 & 2997 \\
\hline $\mathrm{T}-2$ toxin & 31 & 2.8 & $11.7(19.6)$ & 6.83 & 3.7 & 11.1 & 112 \\
\hline HT-2 toxin & 212 & 19.0 & $247(547)$ & 66.4 & 30.3 & 195 & 3712 \\
\hline Diacetoxyscirpenol & 50 & 4.5 & $41.8(75.1)$ & 12.1 & 9.8 & 29.2 & 446 \\
\hline Neosolaniol & 74 & 6.6 & $48.0(144)$ & 11.6 & 7.7 & 23.3 & 912 \\
\hline Fumonisin B1 & 651 & 58.3 & $1990(4350)$ & 496 & 200 & 1549 & 45,922 \\
\hline Fumonisin B2 & 529 & 47.4 & $417(863)$ & 90.6 & 25.3 & 325 & 6875 \\
\hline Fumonisin B3 & 414 & 37.1 & $376(630)$ & 107 & 42.1 & 363 & 3597 \\
\hline Zearalenone & 199 & 17.8 & $560(286)$ & 320 & 77.4 & 781 & 4021 \\
\hline Fusaric acid & 1048 & 93.8 & $660(805)$ & 361 & 151 & 838 & 5194 \\
\hline
\end{tabular}


Table 5. Cont.

\begin{tabular}{|c|c|c|c|c|c|c|c|}
\hline \multirow[b]{2}{*}{ Mycotoxins } & \multicolumn{2}{|c|}{ Samples } & \multicolumn{5}{|c|}{ Concentrations ( $\mu \mathrm{g} / \mathrm{kg})$} \\
\hline & Number & $\%$ & Mean (SD) & Median & 25\% Quartile & 75\% Quartile & Maximum \\
\hline Alternariol & 6 & 0.5 & $47.4(37.7)$ & 34.6 & 25.2 & 71.1 & 104 \\
\hline Patulin & 7 & 0.6 & $422(286)$ & 320 & 223 & 525 & 972 \\
\hline Mycophenolic acid & 38 & 3.4 & $16.8(27.8)$ & 6.8 & 4.3 & 14.0 & 143.6 \\
\hline Roquefortine $\mathrm{C}$ & 20 & 1.8 & $9.2(21.0)$ & 2.1 & 1.9 & 6.1 & 90.8 \\
\hline Penicillic acid & 122 & 10.9 & $192(224)$ & 123 & 65.7 & 205 & 1410 \\
\hline Wortmannin & 4 & 0.4 & $11.9(5.5)$ & 11.2 & 8.0 & 15.2 & 18.6 \\
\hline Gliotoxin & 23 & 2.1 & $278(329)$ & 188 & 78.5 & 312 & 1231 \\
\hline Sterigmatocystin & 24 & 2.1 & $3.5(2.6)$ & 2.9 & 1.9 & 4.4 & 13.2 \\
\hline Verruculogen & 23 & 2.1 & 80.5 (149) & 36.1 & 5.1 & 75.9 & 726 \\
\hline Ergometrine & 22 & 2.2 & $5.7(7.6)$ & 3.1 & 2.5 & 3.9 & 34.2 \\
\hline Ergotamine & 34 & 3.0 & $41.0(72.6)$ & 13.3 & 9.9 & 34.8 & 356 \\
\hline Ergocryptine & 6 & 0.5 & $224(297)$ & 130 & 61.3 & 195 & 811 \\
\hline Lysergol & 52 & 4.7 & $8.8(13.1)$ & 4.9 & 2.5 & 8.3 & 68.5 \\
\hline Methylergonovine & 142 & 12.7 & $3.0(5.2)$ & 1.8 & 1.1 & 3.0 & 54.9 \\
\hline
\end{tabular}

1 3ADON: 3-acetyl-deoxynivalenol; 15ADON: 15-acetyl-deoxynvalenol; D3G: deoxynivalenol-3-glucoside.

Other prevalent mycotoxins included the FBs, with FB1 present in 58.3\%, FB2 in 47.4\% and FB3 in $37.1 \%$ of corn silage samples. Of these three forms, FB1 was detected at the highest concentrations with a mean of $1990 \pm 4350 \mu \mathrm{g} / \mathrm{kg}$, median of $496 \mu \mathrm{g} / \mathrm{kg}$, maximum of $45,900 \mu \mathrm{g} / \mathrm{kg}$, and $75 \%$ quartile of $1549 \mu \mathrm{g} / \mathrm{kg}$. The fungal metabolite of DON, $15 \mathrm{ADON}$, appeared in $39.1 \%$ of samples with a mean concentration of $594 \pm 684 \mu \mathrm{g} / \mathrm{kg}$ (median $342 \mu \mathrm{g} / \mathrm{kg}$ ) and maximum of $3810 \mu \mathrm{g} / \mathrm{kg}$. There was a greater prevalence of HT2 in corn silage $(19.0 \%)$ than grain $(5.9 \%)$. The mean concentration of HT2 in corn silage samples was $247 \pm 547 \mu \mathrm{g} / \mathrm{kg}$ (median $66.4 \mu \mathrm{g} / \mathrm{kg}$ ) and maximum detected concentration of $3710 \mu \mathrm{g} / \mathrm{kg}$. Zearalenone was detected in a slightly lower percentage of corn silage (17.8\%) samples than grain samples, but at a higher mean concentration of $560 \pm 286 \mu \mathrm{g} / \mathrm{kg}$, median of $320 \mu \mathrm{g} / \mathrm{kg}$ and maximum of $4020 \mu \mathrm{g} / \mathrm{kg}$. The top $25 \%$ of samples had ZEA levels above $781 \mu \mathrm{g} / \mathrm{kg}$.

Penicillium mycotoxins, comprising patulin, mycophenolic acid (MPA), roquefortine $\mathrm{C}$ and penicillic acid (PA), had a higher occurrence rate in corn silage than corn grain. Penicillic acid was the primary mycotoxin detected in this group with an occurrence rate of $10.9 \%$. The mean concentration of PA was $192 \pm 224 \mu \mathrm{g} / \mathrm{kg}$, median of $123 \mu \mathrm{g} / \mathrm{kg}$ and maximum of $1410 \mu \mathrm{g} / \mathrm{kg}$, but a $75 \%$ quartile of $205 \mu \mathrm{g} / \mathrm{kg}$. Interestingly, AFB1 was detected in $7.9 \%$ of samples which was greater than corn grain with only $1.7 \%$ of samples containing AFB1. Although the concentrations for AFB1 were lower on average (mean $9.5 \pm 13.0 \mu \mathrm{g} / \mathrm{kg}$, median $4.6 \mu \mathrm{g} / \mathrm{kg}$, $75 \%$ quartile of $11.5 \mu \mathrm{g} / \mathrm{kg}$ ), there was a maximum of $82.4 \mu \mathrm{g} / \mathrm{kg}$ detected in corn silage.

\subsection{Mycotoxins Exceeding Action, Advisory or Guidance Levels}

Mycotoxin action, advisory or guideline limits are provided by the United States Food and Drug Administration (FDA) and European Commission (EC) for corn and cornbased products [8,9]. Although the listed limits may not be relevant for all animal species, investigation of the percentage of both corn grain and silage samples above each limit are provided to assess not only the mycotoxin content but also as a means for comparing the difference between these two feedstuffs (Table 6). Results of corn grain analysis showed that only $0.14 \%$ of corn grain samples had concentrations of AFB1 above $20 \mu \mathrm{g} / \mathrm{kg}$ although the same $0.14 \%$ also exceeded the FDA action level of $300 \mu \mathrm{g} / \mathrm{kg}$ for AFs. Concentrations of DON exceeded $5000 \mu \mathrm{g} / \mathrm{kg}$ in $1.55 \%$ of samples and $8000 \mu \mathrm{g} / \mathrm{kg}$ in $0.98 \%$ of samples. A total of $17.72 \%$ of samples had FBs concentrations that exceeded $5000 \mu \mathrm{g} / \mathrm{kg}, 9.56 \%$ of sample also contained FBs at or above $10,000 \mu \mathrm{g} / \mathrm{kg}, 3.38 \%$ exceeded $20,000 \mu \mathrm{g} / \mathrm{kg}$ but no samples exceeded $60,000 \mu \mathrm{g} / \mathrm{kg}$. Only $0.42 \%$ of corn grain samples had ZEA levels 
exceeding the EC limit of $2000 \mu \mathrm{g} / \mathrm{kg}$, while ochratoxin A (OTA) levels did not exceed the EC suggested regulatory limit.

Table 6. Percentage of analyzed samples with mycotoxin concentrations at or exceeding the United States Food and Drug Administration (FDA) and European Commission (EC) action, advisory or guidance levels for corn, corn products or complete feedstuffs intended for use in animal rations [8,9].

\begin{tabular}{|c|c|c|c|c|c|c|}
\hline & \multicolumn{6}{|c|}{ Mycotoxin Limits, $\mu \mathrm{g} / \mathrm{kg}^{1}$} \\
\hline & AFB1 & AFs & DON & FBs $^{2}$ & ZEA & OTA \\
\hline Limit & $20 *$ & $20 * *$ & $5000 * *$ & $5000 * *$ & $2000 *$ & 250 * \\
\hline$\%$ Grain & 0.14 & 0.14 & 1.55 & 17.72 & 0.42 & - \\
\hline$\%$ Silage & 1.16 & 6.09 & 7.88 & 7.88 & 1.25 & - \\
\hline Limit & & $100 * *$ & $8000 *$ & $10,000 * *$ & & \\
\hline$\%$ Grain & & 0.14 & 0.98 & 9.56 & & \\
\hline$\%$ Silage & & 0.27 & 3.4 & 3.94 & & \\
\hline Limit & & $200 * *$ & $10,000 * *$ & $20,000 * *$ & & \\
\hline$\%$ Grain & & 0.14 & 0.56 & 3.38 & & \\
\hline$\%$ Silage & & 0.18 & 1.88 & 1.07 & & \\
\hline Limit & & $300 * *$ & & $30,000 * *$ & & \\
\hline$\%$ Grain & & 0.14 & & 0.98 & & \\
\hline$\%$ Silage & & 0.09 & & 0.45 & & \\
\hline Limit & & & & $60,000 * * * *$ & & \\
\hline$\%$ Grain & & & & - & & \\
\hline$\%$ Silage & & & & - & & \\
\hline
\end{tabular}

${ }^{1}$ AFB1: aflatoxin B1; AFs: aflatoxin B1 + aflatoxin B2 + aflatoxin G1 + aflatoxin G2; DON: deoxynivalenol; FBs: fumonisin B1 + fumonisin B2 + fumonisin B3; ZEA: zearalenone; OTA: ochratoxin A. ${ }^{2}$ Fumonisins guidance by FDA is based on the sum of fumonisins B1 + B2 + B3, while EC guidance refers to the sum of fumonisins B1 and B2. * EC maximum and guidance levels for cereal and cereal products; ${ }^{* *}$ FDA action, advisory or guidance levels for corn and corn products with different mycotoxin levels corresponding to intended use for different species or age groups.

Aflatoxin B1 concentrations in corn silage were detected above $20 \mu \mathrm{g} / \mathrm{kg}$ in $1.16 \%$ of samples, AFs were detected over $20 \mu \mathrm{g} / \mathrm{kg}$ in $6.09 \%$ of silages but exceeding $300 \mu \mathrm{g} / \mathrm{kg}$ in only $0.09 \%$ of samples (Table 6). There were $7.88 \%$ of samples that had DON over $5000 \mu \mathrm{g} / \mathrm{kg}$, $3.40 \%$ exceeded $8000 \mu \mathrm{g} / \mathrm{kg}$, and $1.88 \%$ of silage samples were over 10,000 $\mu \mathrm{g} / \mathrm{kg}$ DON. The concentration of FBs in corn silage were lower than grain, with only $7.88 \%$ of samples over $5000 \mu \mathrm{g} / \mathrm{kg}, 3.94 \%$ over $10,000 \mu \mathrm{g} / \mathrm{kg}, 1.07 \%$ exceeding $20,000 \mu \mathrm{g} / \mathrm{kg}$ and no samples exceeding $60,000 \mu \mathrm{g} / \mathrm{kg}$. The concentrations of ZEA in corn silage exceeded $2000 \mu \mathrm{g} / \mathrm{kg}$ in $1.25 \%$ of silages. Levels of OTA did not exceed the EC suggested regulatory limit.

\subsection{Mycotoxin Co-Occurrence}

\subsubsection{Frequency of Mycotoxin Pairs}

Most frequencies of co-occurrence among mycotoxin pairs for corn grain were less than 100, although it ranged from 0 to over 400 (Figure 1A). Many of these mycotoxin pairs demonstrated a positive relationship, indicating that frequencies of co-occurrence were greater than an association by random chance $(p<0.05)$. Pairs of mycotoxins that cooccurred less than a random association, i.e., a negative relationship, generally had fewer frequencies of co-occurrence. There was a greater number of significant $(p<0.05)$ positively associated (56) pairs than negatively associated (23) pairs of mycotoxins. Additionally, there were 176 pairs of mycotoxins that had non-significant relationships, or a random association of co-occurrence. 
A
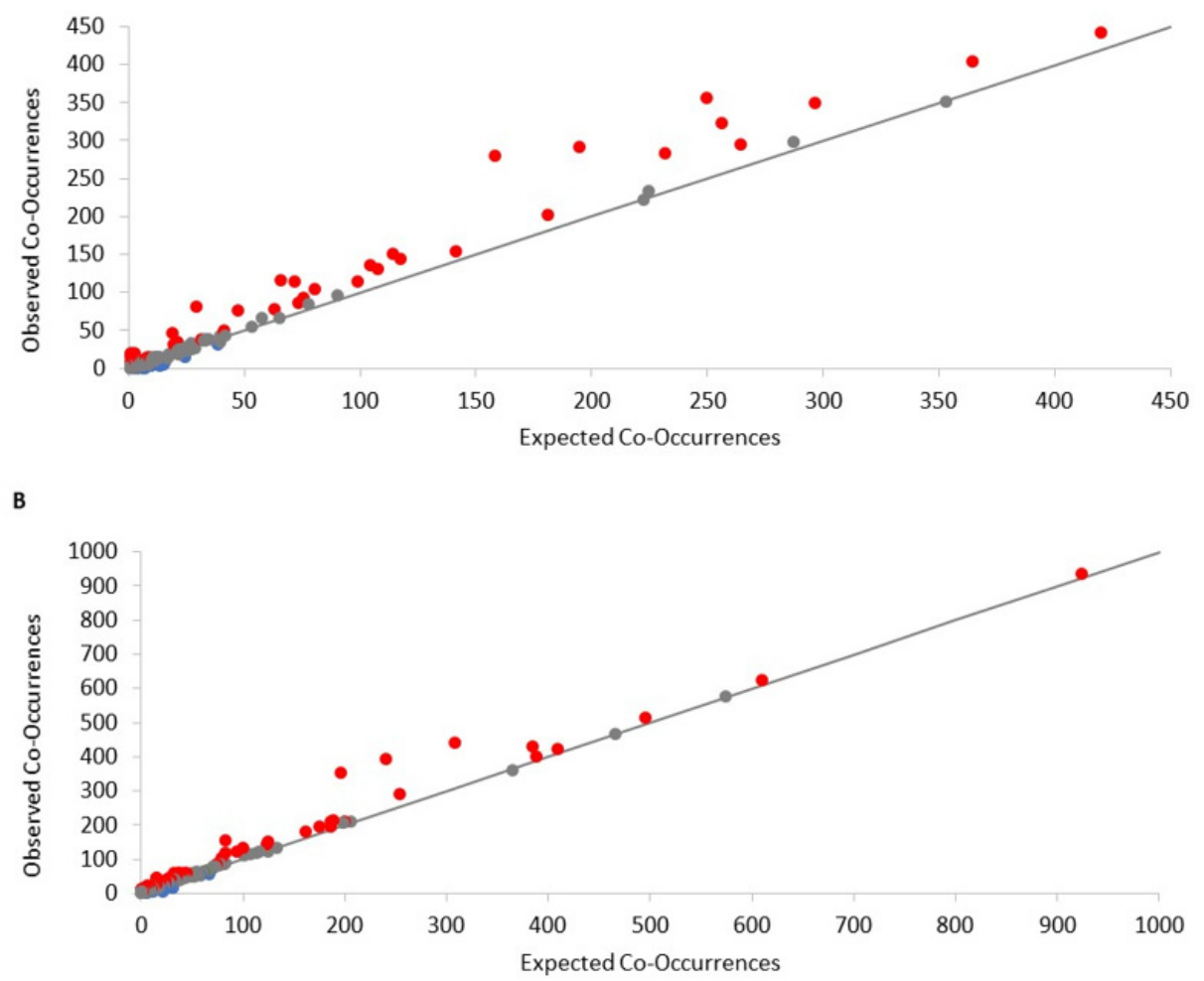

Figure 1. Plots showing the number of incidences of co-occurrence between selected pairs of individual mycotoxins for corn grain (A) and silage (B) samples. Red color depicts mycotoxin pairs with positive co-occurrences that were detected more than $(p<0.05)$ the model expected under a random association, blue depicts pairs with negative co-occurrences that were detected less than $(p<0.05)$ the model expected under a random association, and grey indicates those pairs that were equivalent to what the model expected under a random association.

The distribution of frequencies of co-occurrence among mycotoxin pairs in corn silage (Figure 1B) were similar to corn grain, although there were some pairs with much higher frequencies of co-occurrence at over 900 pairings. There was a greater number of significant $(p<0.05)$ pairs with a positive relationship (87) than pairs with a negative relationship (25). Similar to corn grain, many mycotoxin pairs (294) exhibited a random association in their frequency of occurrence.

\subsubsection{Probability of Mycotoxin Pairs}

For corn grain samples analyzed, the most frequently detected co-occurrence was between DON and FA with a probability of $0.591(p<0.001$; Table 7). Fusaric acid also had a relatively high probability of co-occurrence with FB1 (0.513), FB2 (0.417), FB3 (0.326), and $15 \mathrm{ADON}(0.372, p<0.001)$. Similarly, there was a relatively high probability of cooccurrence between DON and 15ADON $(0.361, p<0.001)$. There were also relatively low, but significant, co-occurrences between DON and 3ADON $(0.106, p<0.001)$ and D3G $(0.147, p<0.001)$. Each of these mentioned pairs demonstrated a positive relationship and co-occurred at frequencies greater than what would be expected by a random association. Conversely, OTA co-occurred with DON $(0.034, p=0.028), 15 \mathrm{ADON}(0.021, p<0.001)$, and D3G $(0.009, p<0.001)$ at frequencies lower than a random association. 
Table 7. Probability of co-occurrence between pairs of 15 individual mycotoxins for corn grain samples. Numbers indicate probability of co-occurrence, bolded values indicate significant $(p<0.05)$ co-occurrence of groups that are detected more than (red), less than (blue) or equivalent to (grey) what the model expected under a random association. Pairs that did not co-occur among samples are blank (white) or not included in the table.

\begin{tabular}{|c|c|c|c|c|c|c|c|c|c|c|c|c|c|c|}
\hline Mycotoxin $^{1}$ & OTA & DON & 3ADON & 15ADON & D3G & T2 & HT2 & FB1 & FB2 & FB3 & ZEA & FA & MPA & PA \\
\hline AFB1 & & 0.013 & 0.002 & 0.008 & 0.003 & & & 0.011 & 0.09 & 0.007 & 0.004 & 0.013 & & \\
\hline OTA & & 0.034 & 0.006 & 0.021 & 0.009 & 0.003 & 0.003 & 0.030 & 0.024 & 0.019 & 0.010 & 0.035 & 0.003 & \\
\hline DON & & & 0.106 & 0.361 & 0.147 & 0.056 & 0.045 & 0.497 & 0.404 & 0.316 & 0.161 & 0.591 & 0.047 & 0.006 \\
\hline $3 \mathrm{ADON}$ & & & & 0.067 & 0.027 & 0.010 & 0.008 & 0.092 & 0.075 & 0.059 & 0.030 & 0.110 & 0.009 & \\
\hline $15 A D O N$ & & & & & 0.093 & 0.036 & 0.028 & 0.313 & 0.255 & 0.199 & 0.101 & 0.372 & 0.030 & 0.004 \\
\hline D3G & & & & & & 0.014 & 0.011 & 0.127 & 0.104 & 0.081 & 0.041 & 0.152 & 0.012 & 0.002 \\
\hline $\mathrm{T} 2$ & & & & & & & 0.004 & 0.049 & 0.040 & 0.031 & 0.016 & 0.058 & 0.005 & \\
\hline HT2 & & & & & & & & 0.039 & 0.032 & 0.025 & 0.013 & 0.046 & 0.004 & \\
\hline FB1 & & & & & & & & & 0.351 & 0.274 & 0.139 & 0.513 & 0.041 & 0.006 \\
\hline FB2 & & & & & & & & & & 0.223 & 0.114 & 0.417 & 0.033 & 0.005 \\
\hline FB3 & & & & & & & & & & & 0.089 & 0.326 & 0.026 & 0.004 \\
\hline ZEA & & & & & & & & & & & & 0.166 & 0.013 & 0.002 \\
\hline FA & & & & & & & & & & & & & 0.048 & 0.007 \\
\hline
\end{tabular}

The results of corn silage analysis identified many similar pairs of mycotoxins that co-occurred more frequently than by chance (Table 8 ). The highest positive association was between DON and FA, with a probability of co-occurrence of $0.827(p<0.01)$. The occurrence of DON with $15 \mathrm{ADON}(0.345, p<0.001)$ and FA with $15 \mathrm{ADON}(0.367, p=0.001)$ were also relatively high in frequency of co-occurrence. Similar to corn grain, FA also had relatively high co-occurrence probabilities with FB1 $(0.513, p<0.001)$, FB2 $(0.417, p<0.001)$ and FB3 $(0.326 p=0.004)$. Furthermore, the mycotoxin pairs of OTA and HT2, OTA and FB2, $15 \mathrm{ADON}$ and MPA, and ZEA with PA, were all detected less frequently than by chance, which is characteristic of a negative relationship.

Table 8. Probability of co-occurrence between pairs of 15 individual mycotoxins for corn silage samples. Numbers indicate probability of co-occurrence, bolded values indicate significant $(p<0.05)$ co-occurrence of groups that are detected more than (red), less than (blue) or equivalent to (grey) what the model expected under a random association. Pairs that did not co-occur among samples are blank (white) or not included in the table.

\begin{tabular}{|c|c|c|c|c|c|c|c|c|c|c|c|c|c|c|}
\hline Mycotoxin $^{1}$ & OTA & DON & 3ADON & 15ADON & D3G & $\mathrm{T} 2$ & HT2 & FB1 & FB2 & FB3 & ZEA & FA & MPA & PA \\
\hline AFB1 & 0.001 & 0.069 & 0.015 & 0.031 & 0.006 & 0.002 & 0.015 & 0.046 & 0.037 & 0.029 & 0.014 & 0.074 & 0.003 & 0.009 \\
\hline OTA & & 0.014 & 0.003 & 0.006 & 0.001 & & 0.003 & 0.009 & 0.008 & 0.006 & 0.003 & 0.015 & & 0.002 \\
\hline DON & & & 0.169 & 0.345 & 0.066 & 0.024 & 0.167 & 0.514 & 0.418 & 0.327 & 0.157 & 0.827 & 0.03 & 0.096 \\
\hline 3ADON & & & & 0.075 & 0.014 & 0.005 & 0.036 & 0.112 & 0.091 & 0.071 & 0.034 & 0.180 & 0.007 & 0.021 \\
\hline $15 \mathrm{ADON}$ & & & & & 0.029 & 0.011 & 0.074 & 0.228 & 0.185 & 0.145 & 0.070 & 0.367 & 0.013 & 0.043 \\
\hline D3G & & & & & & 0.002 & 0.014 & 0.044 & 0.036 & 0.028 & 0.013 & 0.071 & 0.003 & 0.008 \\
\hline $\mathrm{T} 2$ & & & & & & & 0.005 & 0.016 & 0.013 & 0.010 & 0.005 & 0.026 & 0.001 & 0.003 \\
\hline HT2 & & & & & & & & 0.111 & 0.090 & 0.070 & 0.034 & 0.178 & 0.006 & 0.021 \\
\hline FB1 & & & & & & & & & 0.276 & 0.216 & 0.104 & 0.547 & 0.020 & 0.064 \\
\hline FB2 & & & & & & & & & & 0.176 & 0.084 & 0.444 & 0.016 & 0.052 \\
\hline FB3 & & & & & & & & & & & 0.066 & 0.348 & 0.013 & 0.040 \\
\hline ZEA & & & & & & & & & & & & 0.167 & 0.006 & 0.019 \\
\hline FA & & & & & & & & & & & & & 0.032 & 0.102 \\
\hline MPA & & & & & & & & & & & & & & 0.004 \\
\hline
\end{tabular}

${ }^{1}$ AFB1: aflatoxin B1; OTA: ochratoxin A; DON: deoxynivalenol; 3ADON: 3-acetyl-deoxynivalenol; 15ADON: 15-acetyl-deoxynvalenol; D3G: deoxynivalenol-3-glucoside; T2: T-2 toxin; HT2: HT-2 toxin; FB1: fumonisin B1; FB2: fumonisin B2; FB3: fumonisin B3; ZEA: zearalenone; FA: fusaric acid; MPA: mycophenolic acid; PA: penicillic acid.

\subsection{Mycotoxin Variation by Year}

Significant $(p<0.01)$ yearly variations of mycotoxin concentrations in corn grain were observed for all groups except type A trichothecenes and Penicillium mycotoxins (Table 9$)$. The highest mean concentration of type B trichothecenes occurred in $2019(1673.4 \pm 414.2 \mu \mathrm{g} / \mathrm{kg})$, while FBs were greatest in 2018 with a mean of $7205.6 \pm 593.3 \mu \mathrm{g} / \mathrm{kg}$. Mean ZEA concentrations were above $200 \mu \mathrm{g} / \mathrm{kg}$ for all years except 2014 and 2015. Concentrations of AFs were below $5 \mu \mathrm{g} / \mathrm{kg}$ except for $2017(310.1 \pm 301.1 \mu \mathrm{g} / \mathrm{kg})$ and $2019(19.2 \pm 2.9 \mu \mathrm{g} / \mathrm{kg})$. The emerging mycotoxins, although one of the most frequent groups, remained at lower levels, at or below $471.7 \pm 179.1 \mu \mathrm{g} / \mathrm{kg}$ for all years. 
Table 9. Yearly variations in mean (SE) concentrations $(\mu \mathrm{g} / \mathrm{kg})$, and number of samples detected containing each mycotoxin group in corn grain $(n=711)$.

\begin{tabular}{|c|c|c|c|c|c|c|c|c|}
\hline \multirow{2}{*}{ Mycotoxin Groups ${ }^{1}$} & \multicolumn{7}{|c|}{ Harvest Year } & \multirow[b]{2}{*}{$p$-Value } \\
\hline & 2013 & 2014 & 2015 & 2016 & 2017 & 2018 & 2019 & \\
\hline \multicolumn{9}{|l|}{ Concentrations, $\mu \mathrm{g} / \mathrm{kg}$} \\
\hline Aflatoxins, total & $2.3(0.2)$ & 2.9 & $4.1(1.0)$ & $3.1(0.2)$ & $310.1(301.1)$ & $4.7(0.9)$ & $19.2(2.9)$ & $<0.001$ \\
\hline Ochratoxins & $6.4(0.2)$ & $2.7(0.5)$ & $2.1(0.03)$ & 9.7 & - & - & - & $<0.001$ \\
\hline Type B trichothecenes & $437.3(115.1)$ & $897.0(400.0)$ & $283.1(63.1)$ & $799.3(179.6)$ & $1009.0(163.7)$ & $746.5(73.0)$ & $1673.4(414.2)$ & $<0.001$ \\
\hline Type A trichothecenes & $14.1(3.4)$ & $11.3(4.0)$ & $26.8(6.5)$ & $38.4(26.6)$ & $64.2(12.9)$ & $47.7(15.4)$ & $35.5(11.3)$ & 0.092 \\
\hline Fumonisins & $2425.1(297.3)$ & $890.9(382.3)$ & $741.6(185.4)$ & $2734.2(580.2)$ & $4495.0(1426.4)$ & $7205.6(593.3)$ & $1268.8(247.9)$ & $<0.001$ \\
\hline Zearalenone & $243.0(88.4)$ & $93.8(37.2)$ & 15.8 & 344.4 & $446.6(169.5)$ & $402.6(69.8)$ & $228.7(63.0)$ & $<0.001$ \\
\hline Emerging mycotoxins & $327.7(103.0)$ & $471.7(179.1)$ & $71.5(25.2)$ & $140.7(26.1)$ & $284.3(42.6)$ & $158.6(12.9)$ & $225.6(80.2)$ & $<0.001$ \\
\hline Penicillium mycotoxins & $114.6(53.5)$ & $12.7(10.9)$ & $222.1(93.4)$ & $71.2(39.1)$ & $4.5(1.0)$ & $167.2(57.1)$ & $446.5(297.8)$ & 0.289 \\
\hline Aspergillus mycotoxins & $5.3(0.4)$ & 2.5 & - & - & - & $334.0(103.7)$ & 39.6 & $<0.001$ \\
\hline Ergot alkaloids & $5.6(0.9)$ & $3.0(0.8)$ & $3.2(0.6)$ & - & 8.1 & $1.5(0.1)$ & - & 0.008 \\
\hline \multicolumn{9}{|l|}{ No. Positive Samples } \\
\hline Aflatoxins, total & 29 & 1 & 4 & 8 & 2 & 7 & 3 & \\
\hline Ochratoxins & 29 & 6 & 12 & 1 & 0 & 0 & 0 & \\
\hline Type B trichothecenes & 43 & 31 & 28 & 78 & 78 & 230 & 93 & \\
\hline Type A trichothecenes & 15 & 2 & 5 & 6 & 13 & 41 & 12 & \\
\hline Fumonisins & 40 & 30 & 35 & 57 & 46 & 222 & 63 & \\
\hline Zearalenone & 10 & 11 & 1 & 1 & 10 & 59 & 59 & \\
\hline Emerging mycotoxins & 40 & 31 & 22 & 62 & 63 & 252 & 85 & \\
\hline Penicillium mycotoxins & 17 & 3 & 2 & 3 & 2 & 32 & 6 & \\
\hline Aspergillus mycotoxins & 36 & 1 & 0 & 0 & 0 & 6 & 1 & \\
\hline Ergot alkaloids & 9 & 4 & 5 & 0 & 1 & 4 & 0 & \\
\hline
\end{tabular}

${ }^{1}$ Aflatoxins, total: aflatoxin B1 + aflatoxin B2 + aflatoxin G1 + aflatoxin G2; ochratoxins: ochratoxin A + ochratoxin B; type B trichothecenes: deoxynivalenol + 3-acetyl-deoxynivalenol + 15-acetyl-deoxynvalenol + deoxynivalenol-3-glucoside + nivalenol + fusarenon $\mathrm{X}$; type $\mathrm{A}$ trichothecenes: T-2 toxin + HT-2 toxin + diacetoxyscirpenol + neosolaniol; fumonisins: fumonisin B1 + fumonisin B2 + fumonisin B3; emerging mycotoxins: fusaric acid + alternariol; Penicillium mycotoxins: patulin + mycophenolic acid + roquefortine $C+$ penicillic acid; Aspergillus mycotoxins: wortmannin + gliotoxin + sterigmatocystin + verruculogen; ergot alkaloids: ergometrine + ergotamine + ergocryptine + lysergol + methylergonovine.

Concentrations of mycotoxins in corn silage were significantly different $(p<0.05)$ between years for all mycotoxin group types (Table 10). Mean concentrations of AFs were above $20 \mu \mathrm{g} / \mathrm{kg}$ in 2013, 2014, 2016 and 2019. Type B trichothecene means were above $1000 \mu \mathrm{g} / \mathrm{kg}$ for all years, with the maximum mean concentration observed in $2017(2708.5 \pm 266.3 \mu \mathrm{g} / \mathrm{kg})$ and closely followed by $2018(2353.7 \pm 153.2 \mu \mathrm{g} / \mathrm{kg})$. Type A trichothecenes were highest on average in 2017 at $660.3 \pm 138.8 \mu \mathrm{g} / \mathrm{kg}$, as was ZEA $(2233.2 \mu \mathrm{g} / \mathrm{kg})$. Emerging mycotoxins were observed in corn silage at concentrations higher than that of corn grain for all years, ranging between $378.3 \pm 38.4$ and $1778.4 \pm 301.8 \mu \mathrm{g} / \mathrm{kg}$. The Penicillium mycotoxins had the greatest mean concentrations in $2014(214.0 \pm 145.9 \mu \mathrm{g} / \mathrm{kg})$ and $2017(212.9 \pm 68.9 \mu \mathrm{g} / \mathrm{kg})$, while mean Aspergillus mycotoxin concentrations were greater in $2015(722.9 \mu \mathrm{g} / \mathrm{kg})$ and 2019 $(237.6 \mu \mathrm{g} / \mathrm{kg})$.

Mycotoxin groups detected in at least 10 samples for each year for each feedstuff were graphed (Figure 2). This criterion was met for AFs, type B trichothecenes, FBs and emerging mycotoxins. Only corn silage consistently had 10 or more positives for AFs in each year. The mean concentrations of AFs decreased from 2013 to 2018 but were again increased in 2019. Graphing the results for type B trichothecenes showed that the mean mycotoxin concentrations were numerically higher in corn silage than grain. Both feedstuffs had a general upward trend for the mean concentrations of type B trichothecenes, although there was variability between years. Emerging mycotoxins were also shown to have numerically higher mean levels in corn silage than grain. Conversely, FBs did not show a clear pattern for the concentrations in grain versus silage. 
Table 10. Yearly variations in mean (SE) concentrations $(\mu \mathrm{g} / \mathrm{kg})$, and number of samples detected containing each mycotoxin group in corn silage $(n=711)$.

\begin{tabular}{|c|c|c|c|c|c|c|c|c|}
\hline \multirow[b]{2}{*}{ Mycotoxin Groups ${ }^{1}$} & \multicolumn{7}{|c|}{ Harvest Year } & \multirow[b]{2}{*}{$p$-Value } \\
\hline & 2013 & 2014 & 2015 & 2016 & 2017 & 2018 & 2019 & \\
\hline \multicolumn{9}{|l|}{ Concentrations, $\mu \mathrm{g} / \mathrm{kg}$} \\
\hline Aflatoxins, total & $45.3(10.8)$ & 27.5 & $18.4(2.6)$ & $21.5(4.6)$ & $12.5(2.5)$ & $4.4(0.5)$ & $48.1(23.3)$ & $<0.001$ \\
\hline Ochratoxins & $4.8(0.7)$ & $4.6(1.5)$ & $3.2(1.0)$ & 7.0 & 42.4 & 36.7 & 12.2 & 0.023 \\
\hline Type B trichothecenes & $1082.7(189.4)$ & $1974.7(286.7)$ & $1750.9(251.5)$ & $1440.7(171.0)$ & $2708.5(266.3)$ & $2353.7(153.2)$ & $1980.7(192.1)$ & 0.044 \\
\hline Type A trichothecenes & $14.0(3.1)$ & $11.6(4.9)$ & $133.2(35.0)$ & $78.7(30.9)$ & $660.3(138.8)$ & $76.5(9.5)$ & $166.7(34.2)$ & $<0.001$ \\
\hline Fumonisins & $3405.3(1367.0)$ & $421.0(82.1)$ & $2625.1(1035.6)$ & $1530.2(336.8)$ & $2950.3(596.9)$ & $2540.8(271.1)$ & $1252.8(324.7)$ & $<0.001$ \\
\hline Zearalenone & $68.4(19.2)$ & $170.4(30.4)$ & 1253.9 & 1927.3 & 2233.2 & $964.7(109.5)$ & $452.8(55.8)$ & $<0.001$ \\
\hline Emerging mycotoxins & $1109.3(173.5)$ & $1778.4(301.8)$ & $478.0(92.1)$ & $378.3(38.4)$ & $997.1(70.1)$ & $415.2(22.2)$ & $702.1(56.1)$ & $<0.001$ \\
\hline Penicillium mycotoxins & $8.7(1.6)$ & $214.0(145.9)$ & $153.2(20.3)$ & $122.8(46.9)$ & $212.9(68.9)$ & $141.7(15.4)$ & $135.2(49.8)$ & $<0.001$ \\
\hline Aspergillus mycotoxins & $59.5(21.7)$ & 31.3 & 722.9 & 1.6 & 150.2 & $153.8(70.1)$ & 237.6 & $<0.001$ \\
\hline Ergot alkaloids & $12.8(1.2)$ & $10.7(3.2)$ & $10.5(9.2)$ & 5.4 & 11.7 & $11.4(2.7)$ & 209.9 & $<0.001$ \\
\hline \multicolumn{9}{|l|}{ No. Positive Samples } \\
\hline Aflatoxins, total & 11 & 29 & 29 & 24 & 45 & 78 & 21 & \\
\hline Ochratoxins & 6 & 8 & 2 & 4 & 2 & 1 & 1 & \\
\hline Type B trichothecenes & 28 & 42 & 39 & 120 & 202 & 377 & 192 & \\
\hline Type A trichothecenes & 20 & 3 & 12 & 18 & 50 & 163 & 57 & \\
\hline Fumonisins & 25 & 35 & 31 & 74 & 146 & 308 & 133 & \\
\hline Zearalenone & 10 & 25 & 1 & 1 & 1 & 55 & 106 & \\
\hline Emerging mycotoxins & 25 & 43 & 41 & 120 & 209 & 396 & 214 & \\
\hline Penicillium mycotoxins & 4 & 7 & 17 & 21 & 29 & 86 & 16 & \\
\hline Aspergillus mycotoxins & 19 & 13 & 2 & 1 & 3 & 18 & 9 & \\
\hline Ergot alkaloids & 8 & 17 & 5 & 40 & 49 & 100 & 7 & \\
\hline
\end{tabular}

${ }^{1}$ Aflatoxins, total: aflatoxin B1 + aflatoxin B2 + aflatoxin G1 + aflatoxin G2; ochratoxins: ochratoxin A + ochratoxin B; type B trichothecenes: deoxynivalenol + 3-acetyl-deoxynivalenol + 15-acetyl-deoxynvalenol + deoxynivalenol-3-glucoside + nivalenol + fusarenon $\mathrm{X}$; type $\mathrm{A}$ trichothecenes: T-2 toxin + HT-2 toxin + diacetoxyscirpenol + neosolaniol; fumonisins: fumonisin B1 + fumonisin B2 + fumonisin B3; emerging mycotoxins: fusaric acid + alternariol; Penicillium mycotoxins: patulin + mycophenolic acid + roquefortine $C+$ penicillic acid; Aspergillus mycotoxins: wortmannin + gliotoxin + sterigmatocystin + verruculogen; ergot alkaloids: ergometrine + ergotamine + ergocryptine + lysergol + methylergonovine.

A. Total aflatoxins

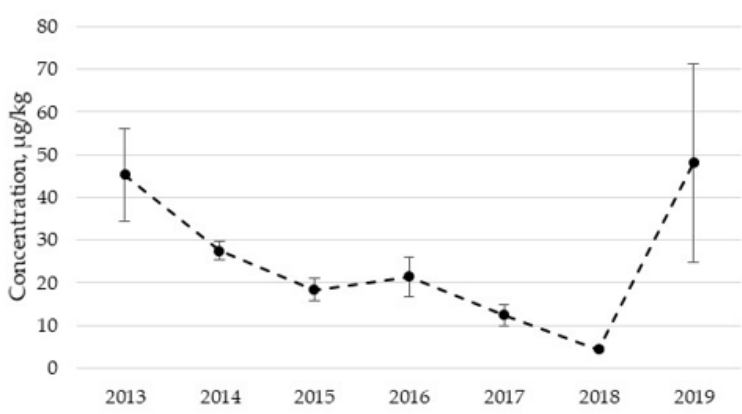

C. Fumonisins

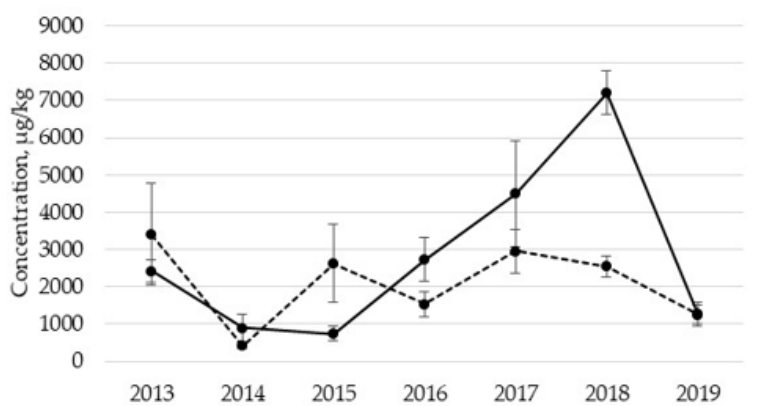

B. Type B trichothecenes

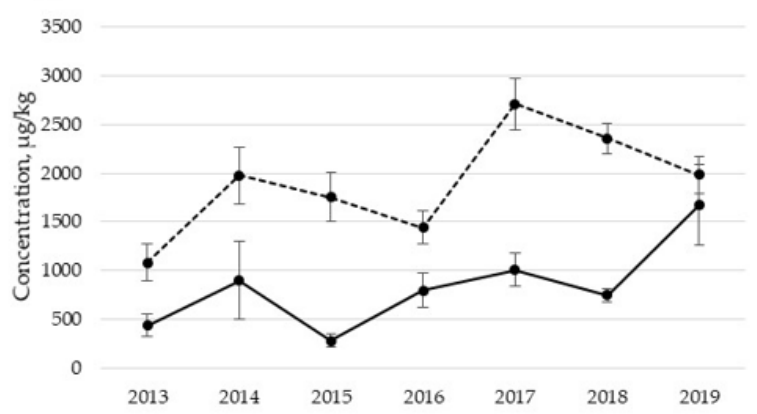

D. Emerging mycotoxins

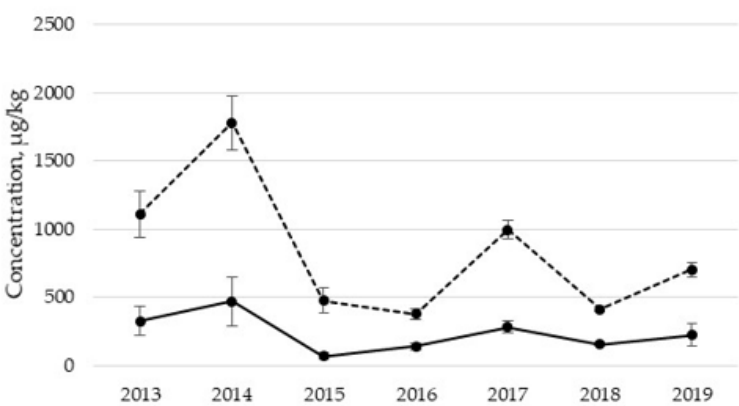

Figure 2. Yearly variation from 2013 to 2019 in concentrations ( $\mu \mathrm{g} / \mathrm{kg}$ ) of total aflatoxins (A), type B trichothecenes (B), fumonisins (C) and emerging mycotoxins (D) in corn grain (solid line) and silage (dashed line). Total aflatoxins are the sum of aflatoxin B1 + aflatoxin B2 + aflatoxin G1 + aflatoxin G2, type B trichothecenes is the sum of deoxynivalenol + 3-acetyl-deoxynivalenol + 15-acetyl-deoxynvalenol + deoxynivalenol-3-glucoside + nivalenol + fusarenon $X$, fumonisins is the sum of fumonisin B1 + fumonisin B2 + fumonisin B3, and emerging mycotoxins the sum of fusaric acid + alternariol. Values show mean \pm SE for each year. Each year represents new crop samples collected between September and December of each year. Only mycotoxins for which there were 10 or more positive results for each year per feedstuff are shown. 


\section{Discussion}

Corn, as both a grain and forage source, is an important component of rations for livestock. However, this crop is susceptible to contamination with mycotoxins which can adversely impact the performance and health of animals. When naturally mycotoxin contaminated feedstuffs are consumed, unexpected health challenges can be observed including, but not limited to, gastrointestinal and internal organ damage, immune suppression, altered reproductive performance, lowered antioxidant status, reduced growth rates and poorer feed efficiency $[10,11]$. Mycotoxins do not need to be consumed at high levels to result in challenges to the animal. In fact, exposure to mycotoxins chronically and/or at lower concentrations that are below levels suggested by regulatory organizations, can negatively impact animal performance $[7,12]$. Furthermore, consumption of multiple mycotoxins simultaneously can further increase risk to the animal [12-14]. As a result, even minimal exposure to multiple mycotoxins could impact the efficiency and profitability of a farm.

Multiple mycotoxins were the norm in the samples analyzed, with around 5 mycotoxins per sample on average for both corn grain and corn silage and up to 12 or 13 mycotoxins present, respectively. Furthermore, $90.2 \%$ of grains and $96.5 \%$ of silages had at least two mycotoxins. Surveys completed in other countries investigating mycotoxin occurrence have also shown a presence of multiple mycotoxins in feedstuffs. In Belgium, whole plant corn silage analyzed over a three-year period had five or more mycotoxins in $46.7 \%$ of samples [5]. Reisinger et al. [15] reported an average of 13 mycotoxins in corn silage, with $87 \%$ of samples containing at least 5 mycotoxins out of the 61 mycotoxins analyzed.

Our present analysis reports the mycotoxin levels in both feedstuff types around harvest. It was clear that most mycotoxins detected at this timepoint were Fusarium mycotoxins, which made up the top 11 mycotoxins detected in grain and the top 9 mycotoxins detected in silage. The most prevalent mycotoxin was FA, one of the emerging mycotoxins, in $78.1 \%$ of corn grain and $93.8 \%$ of silage samples. Fusaric acid is an unusual mycotoxin in that it can be produced by at least 12 different Fusarium species [16]. As such, FA has been speculated to be one of the most widely produced mycotoxins. We confirmed this speculation in our survey, but FA may not always be the most frequent. Reisinger et al. [15] reported only $22 \%$ of 158 corn silage samples were positive for FA although more than $70 \%$ of samples contained other emerging mycotoxins such as beauvericin and enniatins. Although consumption of FA by animals can elevate brain serotonin levels, decrease blood pressure and act as a chelating agent that could be involved in abnormal bone formation, it does appear to have lower toxicity than other mycotoxins such as AF, DON or T2 [17-19].

The other two top mycotoxins detected in this survey were DON and FB1 which were present in 75.7 or $65.7 \%$ of grain and 88.2 or $58.3 \%$ of silage samples, respectively. In accordance with our results, DON and FBs are also shown to be frequently detected mycotoxins in European feeds for poultry with a prevalence of $98 \%$ and $100 \%$, respectively [7]. Assessment of imported raw corn grain from the US to Korea also showed a high occurrence of DON and FB1, both in $100 \%$ of samples [20].

When investigating the frequency of these most prevalent Fusarium mycotoxins to exceed regulatory guidelines, $1.6 \%$ of corn grain had over $5000 \mu \mathrm{g} / \mathrm{kg}$ DON which is the FDA guidance for DON contaminated grains for swine [8]. This guidance states that corn and corn products exceeding $5000 \mu \mathrm{g} / \mathrm{kg}$ should be included at no more than $20 \%$ of the ration in order to limit total ration DON intake to $1000 \mu \mathrm{g} / \mathrm{kg}$. Only $0.98 \%$ of grains had over $8000 \mu \mathrm{g} / \mathrm{kg}$, the EC guidance level, with stipulations for complete rations not to exceed $900 \mu \mathrm{g} / \mathrm{kg}$ for pigs [9]. When considering corn silage, $3.4 \%$ of samples exceeded the EC limit of $8000 \mu \mathrm{g} / \mathrm{kg}$ while $1.9 \%$ exceeded the $10,000 \mu \mathrm{g} / \mathrm{kg}$ FDA advisory level for grains for poultry and ruminants, which should not exceed $50 \%$ in the final ration. Similarly, Birr et al. [21] reported that $9 \%$ of corn silage from Germany exceeded $5000 \mu \mathrm{g} / \mathrm{kg}$. Despite fewer samples having very high DON levels, we did find that the mean concentration of DON in corn grain samples was $840 \mu \mathrm{g} / \mathrm{kg}$. The presence of any level of DON, whether at lower or higher levels, could be problematic for animal health and performance. In fact, 
pigs consuming $900 \mu \mathrm{g} / \mathrm{kg}$ were shown to have reduced average daily gain as well as intestinal tract changes characterized by reduced villus height, increased crypt depth, and altered intestinal barrier function [22]. A meta-analysis by Holanda and Kim [23] showed that the consumption of $1000 \mu \mathrm{g} / \mathrm{kg}$ DON by pigs reduced average daily gain by $8.9 \%$ while House et al. [24] indicated that the same concentration of DON could significantly increase the number of days required for female pigs to reach $110 \mathrm{~kg}$. Broilers consuming feed with DON at $2264 \mu \mathrm{g} / \mathrm{kg}$ have also shown reduced gain and increased feed conversion ratio [25]. In dairy cows, it is suggested that cows consuming dietary DON $\geq 6740 \mu \mathrm{g} / \mathrm{kg}$ can have 3.7 times greater abortion rates while dietary DON $\geq 3210 \mu \mathrm{g} / \mathrm{kg}$ may increase the percent of cows with endometritis by 1.9 times [26].

Fumonisin guidelines are provided by both FDA and EC. Our survey indicated a potential for FBs to exceed guidance levels, with $17.7 \%$ of samples containing FBs concentrations over the $5000 \mu \mathrm{g} / \mathrm{kg}$ FDA guidance level for corn designated for horses and rabbits. These grains should not exceed $20 \%$ of the diet [8]. Horses are particularly sensitive to FBs and may develop equine leukoencephalomalacia, a neurotoxic disease, if exposed [27]. We observed fewer samples that exceeded FBs levels suggested for other animal groups, with only $3.38 \%$ of grains exceeding the $20,000 \mu \mathrm{g} / \mathrm{kg}$ FDA guidance level for corn designated for swine and catfish and only $0.98 \%$ (grain) and $0.45 \%$ (silage) exceeded the $30,000 \mu \mathrm{g} / \mathrm{kg}$ guidance for corn for breeding ruminants and poultry. Although few samples exceeded these higher levels of FBs, research suggests that lower levels could impact animal health. The consumption of FBs as low as $5000 \mu \mathrm{g} / \mathrm{kg}$ are shown to increase E. coli colonization in the colon of pigs [28].

Our data also shows that ZEA could be a problematic mycotoxin in some cases as it contaminated about $20 \%$ of corn grain and silage. Guidance levels for ZEA are not currently provided by FDA, but $1.25 \%$ of silages contained over the EC guidance of $2000 \mu \mathrm{g} / \mathrm{kg}$. Generally, ZEA consumption is not considered to impact growth performance, and in fact may even improve growth performance outcome, but ZEA does play a role in other areas of health [23]. For example, Wu et al. [29] showed that ZEA at $200 \mu \mathrm{g} / \mathrm{kg}$ can reduce serum immunoglobulins, increase inflammatory cytokines, and reduce concentrations of luteinizing hormone and estradiol in gilts. Additionally, dairy cows may be 1.8 times more likely to develop hyperketonemia when consuming dietary ZEA $\geq 90 \mu \mathrm{g} / \mathrm{kg}$ [26]. Although not considered for regulatory purposes, our data did show that $11.3 \%$ of grain and $12.6 \%$ of silage samples contained ZEA that exceeded $100 \mu \mathrm{g} / \mathrm{kg}$. Depending on feedstuff inclusion rate in the ration, animal performance could be influenced by this presence of ZEA.

Fewer mycotoxins analyzed belonged to the Aspergillus or Penicillium groups. Aflatoxin B1, most frequently produced by Aspergillus flavus, is one of the most widely regulated mycotoxins globally [30]. This mycotoxin was detected in only $1.7 \%$ of grain and $7.9 \%$ of silage samples. The low occurrence rates may have been because a higher percentage of samples were received from Northern, rather than Southern, US locations. Aflatoxin is considered to be more prevalent in the Southern US, although it could occur in any region experiencing high temperatures and drought stress [3]. Furthermore, the distribution of AFs tends to be more heterogeneous in a feedstuff as opposed to a mycotoxin such as DON with a more uniform contamination pattern [31]. Despite AFB1 having a lower occurrence rate, it is still important to consider this mycotoxin for its impacts on animal health and associated human health through the direct consumption of contaminated plant or animal products such as milk. In fact, we did observe that $0.14 \%$ of grain and $1.2 \%$ of silage samples did contain over $20 \mu \mathrm{g} / \mathrm{kg}$, the maximum level set by EC for grains and grain products [9]. The FDA action level for corn and corn products for immature animals, pets and dairy cattle is for AFs at $20 \mu \mathrm{g} / \mathrm{kg}$, which we detected at over this level in $0.14 \%$ (grain) and $6.1 \%$ (silage) of samples [8]. As such, silage appears to be more likely to contain AFs but may not contain concentrations at any higher levels than grain.

Other mycotoxins in the Penicillium and Aspergillus groups can play an important role during storage of feedstuffs. These molds can grow at a wider range of $\mathrm{pH}$, water 
activity and temperatures than Fusarium species, and thus are more abundant during storage [32]. Silages are higher moisture feedstuffs which increases the risk of mold growth. If silages are poorly fermented, have poor packing density or are not covered adequately, the risk of mycotoxin production can be further increased in addition to a decrease of the nutritional value of the poorly preserved and contaminated silage. In our survey, we did not observe high frequencies or high concentrations of these storage type mycotoxins. This observation is likely because we were focused on assessing new crop quality with fresh corn silage samples being collected and submitted for mycotoxin analysis at, or shortly after, harvest. As a result, these silage samples did not have an opportunity to be influenced by typical farm storage conditions. Although silage samples contained only about half a mycotoxin more than corn grain in our samples, it would be interesting to conduct further analysis and determine if the number of mycotoxins, or their concentrations, increase throughout storage.

Ergot alkaloids, produced by members of the genus Claviceps, are known to develop in small grains such as wheat, oats, and barley [33]. These toxins may also be present in grasses. Interestingly, the ergot alkaloid methylergonovine was observed in $12.7 \%$ of corn silage samples in our survey. Methylergonovine is a derivative of ergonovine and is used therapeutically for routine management of postpartum uterine atony and hemorrhage [33]. Although small grains are susceptible to ergot contamination, the only ergot producing fungus shown to develop in corn is Claviceps gigantea, which appears to be geographically limited to high altitudes of Mexico [34]. The ergot alkaloids we detected is more likely a result of cross contamination by other plants in the field such as the presence of small grains or weeds. In fact, Naude et al. [35] reported that after extensive investigation, the contamination of corn silage with ergot alkaloids was due to the presence of yellow nut sedge. Yellow nut sedge is a common weed found worldwide and is known to be frequently contaminated with Claviceps cyperi which can produce ergot alkaloids [35,36]. As such, silage samples analyzed in our survey may have contained weeds such as yellow nut sedge, which not only add to the mycotoxin content of a particular feedstuff but also increase the multiple mycotoxin risk of the whole ration.

Assessing combinations of mycotoxins may be even more important than detecting mycotoxins individually as there are many mycotoxins that may have additive, synergistic or even antagonistic interactions [17,37-40]. In both corn grain and corn silage, the most frequently encountered mycotoxin pair was DON and FA which occurred together in 59.1\% (grain) and $82.7 \%$ (silage) of contaminated samples. Furthermore, our analysis demonstrated that the frequency of their co-occurrence was higher than a random association. Particularly for silage, due to the high probability of co-occurrence, it may be assumed that when there is a presence of one of these mycotoxins there will also be a presence of the other. The co-occurrence of DON and FA together in feedstuffs could be harmful for animal performance and health. These two mycotoxins are suspected to have synergistic relationships and when consumed simultaneously by pigs are shown to further depress weight gain compared to the mycotoxins individually [17]. A suspected mechanism of toxicological synergism between FA and DON relates to tryptophan metabolism. Tryptophan is primarily carried through the blood bound to albumin, but only free tryptophan can cross the blood-brain barrier. Fusaric acid is shown to compete with tryptophan for albumin binding sites resulting in increased unbound tryptophan [17]. As a result, there are increased levels of free tryptophan which is taken up by the brain and used to synthesize serotonin. Although DON and other trichothecenes do not alter the tryptophan concentration, they are shown to increase the serotonin turnover in the hypothalamus to result in DON-induced feed refusal and lethargic behavior [41]. As a result of these complementary actions, the interaction between DON and FA could cause animals to display greater symptoms of DON toxicity than would be expected based on the mycotoxin analysis of feedstuffs or rations.

We also observed that FA co-occurred at a high rate with FB1 in over $51 \%$ of corn grain $(51.3 \%)$ and silage $(54.7 \%)$ samples. Again, this prevalence of co-occurrence was 
found at a significantly greater rate than what would be expected by a random model. Since FA is uniquely produced by a number of different Fusarium species, particularly F. moniliforme which also is the primary producer of FB1, it is likely that FA will be present with other Fusarium mycotoxins $[16,42]$. Interestingly, there was no significant relationship of co-occurrence between DON and FB1 indicating a random association, although they did occur together at a higher rate in about $50 \%$ of samples. Despite the lack of a significant relationship, the presence of these two mycotoxins together could still impact animal performance and are shown to further the negative effects on internal organs, immunity and body weight when consumed together than alone [43,44].

When considering the risk from type B trichothecenes, DON should not be the only mycotoxin to consider. Our survey showed the co-occurrence of DON with other type $\mathrm{B}$ trichothecenes, including the two acetylated derivatives of DON, 3ADON and 15ADON. It is expected that these three toxins will appear together as they are produced by the same fungal biosynthetic pathway [45]. Other survey data has shown a strong correlation between DON and its derivatives [5]. Our results also showed that 15ADON was more prevalent than $3 \mathrm{ADON}$, which is important when considering mycotoxicosis to an animal. In fact, $15 \mathrm{ADON}$ is shown to have higher toxicity than $3 \mathrm{ADON}$, and higher or equal toxicity to DON, resulting in more histological lesions in the intestine both ex vivo and in vivo $[38,46]$. Furthermore, the co-contamination of DON with $15 \mathrm{ADON}$, which in our survey co-occurred in $36.1 \%$ (grain) and $34.5 \%$ (silage) of samples, can further increase toxicity with these mycotoxins being shown to have additive and synergistic effects but could also have some antagonistic relationships depending on the mycotoxin concentrations [38]. Vandicke et al. [5,47] saw that the concentrations of DON and 15ADON have strongly positive correlation coefficients in both fresh $(r=0.70)$ and ensiled $(r=0.79)$ corn silage over a three-year period. As such, their research showed that the concentrations are linked, while our research showed that they have a reasonably high rate of co-occurrence. Although regulatory levels are based on DON only, the presence of DON derivatives and conjugates, such as $15 \mathrm{ADON}$, should be considered when assessing total mycotoxin risk.

The strong positive probability of co-occurrence between many of the mycotoxin pairs may be an indication of similar environmental conditions required for molds to produce mycotoxins, the prevalence of the different mold types or the types of mycotoxins a mold can produce. As mentioned previously, FA can be produced by a variety of different mold types [16]. As such, FA may be produced under a variety of climatic conditions leading to its high co-occurrence with other mycotoxins. Conversely, the production of DON and FBs are promoted by contrasting environmental conditions [48]. These two mycotoxins may have a high rate of co-occurrence, which we observed in both corn grain and silage, but there was a random association with no significant relationship between the two. Furthermore, the contamination of OTA with Fusarium mycotoxins was most likely to result in co-occurrence that was observed to a lesser extent than what would be expected randomly. Interestingly, OTA production in cereals is assumed to be from Penicillium verrucosum in temperate regions such as Europe and Canada [48]. Infection of this mold and its production of OTA is thought to occur only post-harvest during the drying stage when there is slow drying in conjunction with rain or fog. This somewhat different contamination pattern of OTA versus other mycotoxins could lead to the observed lower co-occurrence rates.

Yearly variations in occurrence and concentration of mycotoxin groups were observed. Environmental conditions during plant growth and harvest play a significant role in yearto-year variation of mycotoxin type and content. Furthermore, different weather conditions may lead to varying mycotoxin profiles. For example, the production of AFs and FBs are associated with preharvest drought stress while DON is produced during periods of excess moisture at anthesis [48]. As such, it was anticipated that there could be yearly variations because of fluctuating weather patterns.

Based on our data, we observed a general upward trend in the concentrations of type B trichothecenes, with 2017, 2018 and 2019 containing the higher mean levels of this mycotoxin group. Historical data reported by the National Oceanic and Atmospheric 
Administration (NOAA) indicate an upward trend in precipitation levels in the contiguous U.S., with 2019 being the second wettest year on record since 1973 [49]. Mueller at al. [50] reported that weather in the United States in 2018 was characterized by unfavorably wet conditions and delayed harvest which resulted in an estimated 2.5 billion bushels of corn grain contaminated with mycotoxins. Our survey showed frequent mycotoxin contamination of grain and silage in 2018, although 2018 was not necessarily the year with highest mean levels of contamination. Interestingly, AFs in corn silage were also shown to have a higher mean level in 2019. Typically, AFs are shown to develop during dryer conditions. This response may have been a result of localized drought conditions despite the general U.S. having higher precipitation, or this increase in AFs may have occurred at or after harvest rather than in the field. It should be noted that there were higher numbers of samples of grain and silage collected in 2016 through 2019 than in 2013-2015. This difference in sample number could have played a role in the detection of mycotoxins.

Regarding the difference between corn grain and silage, it was observed that silage typically had greater yearly concentrations of mycotoxins than grain. Research in wheat showed DON contamination levels to be greatest in glumes and straw, and significantly lower in the grain [51]. In corn, Fusarium mycotoxins are reported to contaminate leaves and stalks more than kernels [52]. Investigation of Fusarium colonization on ears and stalks of corn showed that some species tend to grow on the grain while others are more inclined to grow on stalks, whereas others such as F. graminearum are likely to develop on both ears and stalks but are highly dependent on plant growth stage and environmental conditions [53]. It is reasonable to assume that silage could have higher mold and mycotoxin levels due to the nature of including both stems and leaves which not only increases surface area exposed but may also bring in additional contamination sources such as mold contaminated soil. An exception for this tendency for higher mycotoxins in silage was with FBs, where corn grain and silage did not show a clear pattern of one containing higher concentrations than the other which may have been due to a variety of factors including the timing of weather events promoting FBs development.

\section{Conclusions}

Results of our survey represent a snapshot of the mycotoxin contamination of corn grain and corn silage at harvest from across the United States between 2013 and 2019. A total of 711 corn grain and 1117 corn silage samples were analyzed for the presence of 35 mycotoxins. Multiple mycotoxin contamination was the norm, with a mean of about five mycotoxins per sample. The majority of mycotoxins detected in this survey are considered to be produced during field growth of the crop, while the presence of storagetype mycotoxins was minimal. However, certain mycotoxins are known to increase during storage and a next step would be for future surveys to track mycotoxins throughout storage. Mycotoxin concentrations did vary by year, as expected due to the role that environmental conditions can play on mold growth and mycotoxin development.

Fusarium mycotoxins were prevalent, with FA, DON, FBs and $15 \mathrm{ADON}$ being the most frequently observed mycotoxins in both grain and silage. These mycotoxins had high rates of co-occurrence. The most frequent pair was DON and FA in 59\% of grain and $83 \%$ of silage samples. The presence of FB1 with FA was just over $50 \%$, while there was also a relatively high co-occurrence between DON and its metabolite 15ADON. Each of these interactions resulted in co-occurrences that occurred more than what would be expected by random association. The presence of multiple mycotoxins could lead to an increase in detrimental effects to the animal upon consumption of contaminated feed materials. Furthermore, some samples contained concentrations of mycotoxins above guidelines indicated by governing agencies, particularly DON and FBs. Considering the presence of higher concentrations of mycotoxins in both grain and silage, the frequent co-occurrence of several important Fusarium mycotoxins, as well as the yearly variability of mycotoxins, the assessment and quantification of multiple mycotoxins in both corn grain and silage should be considered routine when developing a mycotoxin control program. 


\section{Materials and Methods}

\subsection{Sample Collection}

A total of 711 corn grain and 1117 corn silage samples that represented 7 harvests from 2013 to 2019 (samples collected between September and December of each year) were collected from across the United States (Table 11). Samples were submitted on a voluntary basis from animal production farms and animal feed production facilities to the Alltech Annual Harvest Analysis Survey. This survey focuses on assessing mycotoxin risk in new crop samples each year. Instructions for proper sampling procedures based on methods described by the USDA Grain Inspection Handbook [54] and Undersander et al. [55] were available to individuals collecting samples. These procedures outline the process of collecting subsamples and creating a final homogenous sample. Submission instructions specified that each sample be packaged to preserve the integrity of mycotoxin contents (i.e., double bagged, vacuum sealed, and refrigerated at $<4{ }^{\circ} \mathrm{C}$ ). It was recommended that samples be immediately submitted to the laboratory after collection and sent via overnight shipping. A final weight of $200-400 \mathrm{~g}$ was requested for samples sent to the laboratory for mycotoxin analysis.

Table 11. Distribution of samples by commodity, geographic origin, and year.

\begin{tabular}{|c|c|c|}
\hline & Number of Samples $(n)$ & Proportion (\%) \\
\hline \multicolumn{3}{|l|}{ Corn Grain } \\
\hline Total number of samples & 711 & \\
\hline \multicolumn{3}{|l|}{ Region } \\
\hline Midwest & 358 & 50.4 \\
\hline Northeast & 201 & 28.3 \\
\hline Southeast & 125 & 17.6 \\
\hline Southwest & 14 & 2.0 \\
\hline Western & 13 & 1.8 \\
\hline \multicolumn{3}{|l|}{ Harvest Year } \\
\hline 2013 & 51 & 7.2 \\
\hline 2014 & 35 & 4.9 \\
\hline 2015 & 48 & 6.8 \\
\hline 2016 & 117 & 16.5 \\
\hline 2017 & 83 & 11.7 \\
\hline 2018 & 274 & 38.5 \\
\hline 2019 & 103 & 14.5 \\
\hline \multicolumn{3}{|l|}{ Corn Silage } \\
\hline Total number of samples & 1117 & \\
\hline \multicolumn{3}{|l|}{ Region } \\
\hline Midwest & 539 & 48.3 \\
\hline Northeast & 286 & 25.6 \\
\hline Southeast & 69 & 6.2 \\
\hline Southwest & 20 & 1.8 \\
\hline Western & 203 & 18.2 \\
\hline \multicolumn{3}{|l|}{ Harvest Year } \\
\hline 2013 & 28 & 2.5 \\
\hline 2014 & 46 & 4.1 \\
\hline 2015 & 44 & 3.9 \\
\hline 2016 & 158 & 14.1 \\
\hline 2017 & 218 & 19.5 \\
\hline 2018 & 405 & 36.3 \\
\hline 2019 & 218 & 19.5 \\
\hline
\end{tabular}

Corn sample locations represented 26 states, with the majority coming from the Midwestern United States (50.4\%), followed by the Northeast (28.3\%) and Southeast (17.6\%). Only a small proportion of corn samples submitted for analysis were sourced from the Southwest $(2.0 \%)$ or West $(1.8 \%)$. Samples of corn silage were sourced from 36 states and primarily submitted from the Midwest $(48.3 \%)$, Northeast $(25.6 \%)$ or West $(18.2 \%)$. Fewer samples were received from the Southeast $(6.2 \%)$ or Southwest $(1.8 \%)$. 


\subsection{Mycotoxin Quantification}

A total of 35 individual mycotoxins were analyzed for each corn grain or corn silage sample submitted (Table 12). These mycotoxins were grouped into 10 groups: total aflatoxins (AFB1 + aflatoxin B2 + aflatoxin G1 + aflatoxin G2), ochratoxins (OTA + ochratoxin B), type $\mathrm{B}$ trichothecenes $(\mathrm{DON}+3 \mathrm{ADON}+15 \mathrm{ADON}+\mathrm{D} 3 \mathrm{G}+$ nivalenol + fusarenon $\mathrm{X})$, type A trichothecenes (T2 + HT2 + diacetoxyscirpenol + neosolaniol), fumonisins (FB1 + FB2 + FB3), ZEA, emerging mycotoxins (FA + alternariol), Penicillium mycotoxins (patulin + MA + roquefortine C + PA), Aspergillus mycotoxins (wortmannin + gliotoxin + sterigmatocystin + verruculogen), ergot alkaloids (ergometrine + ergotamine + ergocryptine + lysergol + methylergonovine).

Table 12. Analyzed mycotoxins, lowest limit of detection or quantification by ultra-pressure liquid chromatography-tandem mass spectrometry.

\begin{tabular}{|c|c|c|c|c|c|}
\hline & Mycotoxin Group & Mycotoxins & Abbreviation & $\begin{array}{l}\text { Lowest Limit of } \\
\text { Detection, } \mu \mathrm{g} / \mathrm{kg}\end{array}$ & $\begin{array}{c}\text { Lowest Limit of } \\
\text { Quantification, } \mu \mathrm{g} / \mathrm{kg}\end{array}$ \\
\hline 1 & \multirow[t]{4}{*}{ Total Aflatoxins } & Aflatoxin B1 & AFB1 & 0.129 & 0.429 \\
\hline 2 & & Aflatoxin B2 & AFB2 & 0.684 & 2.281 \\
\hline 3 & & Aflatoxin G1 & AFG1 & 0.449 & 1.495 \\
\hline 4 & & Aflatoxin G2 & AFG2 & 0.422 & 1.408 \\
\hline 5 & \multirow[t]{2}{*}{ Ochratoxins } & Ochratoxin A & OTA & 0.362 & 1.208 \\
\hline 6 & & Ochratoxin B & ОТВ & 0.302 & 1.008 \\
\hline 7 & \multirow[t]{6}{*}{$\begin{array}{c}\text { Type B } \\
\text { Trichothecenes }\end{array}$} & Deoxynivalenol & $\mathrm{DON}$ & 5.713 & 19.044 \\
\hline 8 & & 3-acetyl-deoxynivalenol & 3ADON & 4.058 & 13.526 \\
\hline 9 & & 15- acetyl-deoxynivalenol & $15 \mathrm{ADON}$ & 7.442 & 24.806 \\
\hline 10 & & Deoxynivalenol-3-glucoside & D3G & 16.651 & 55.50 \\
\hline 11 & & Nivalenol & NIV & 53.988 & 179.960 \\
\hline 12 & & Fusarenon $X$ & $\mathrm{FX}$ & 2.489 & 8.295 \\
\hline 13 & \multirow{4}{*}{$\begin{array}{c}\text { Type A } \\
\text { Trichothecenes }\end{array}$} & T-2 toxin & $\mathrm{T} 2$ & 0.744 & 2.481 \\
\hline 14 & & HT-2 toxin & HT2 & 2.296 & 7.655 \\
\hline 15 & & Diacetoxyscirpenol & DAS & 1.505 & 5.017 \\
\hline 16 & & Neosolaniol & NEO & 0.946 & 3.154 \\
\hline 17 & \multirow[t]{3}{*}{ Fumonisins } & Fumonisin B1 & FB1 & 20.426 & 68.086 \\
\hline 18 & & Fumonisin B2 & FB2 & 1.804 & 6.012 \\
\hline 19 & & Fumonisin B3 & FB3 & 2.918 & 16.493 \\
\hline 20 & \multirow{3}{*}{$\begin{array}{l}\text { Zearalenone } \\
\text { Emerging } \\
\text { Mycotoxins }\end{array}$} & Zearalenone & ZEA & 2.545 & 8.482 \\
\hline 21 & & Fusaric acid & FA & 0.017 & 0.055 \\
\hline 22 & & Alternariol & ALT & 1.379 & 4.598 \\
\hline 23 & \multirow[t]{4}{*}{$\begin{array}{l}\text { Penicillium } \\
\text { Mycotoxins }\end{array}$} & Patulin & PAT & 16.669 & 55.562 \\
\hline 24 & & Mycophenolic acid & MPA & 2.496 & 8.319 \\
\hline 25 & & Roquefortine C & ROQC & 0.196 & 0.653 \\
\hline 26 & & Penicillic acid & PEN & 11.693 & 38.978 \\
\hline 27 & \multirow[t]{4}{*}{$\begin{array}{l}\text { Aspergillus } \\
\text { Mycotoxins }\end{array}$} & Wortmannin & WORT & 0.764 & 2.545 \\
\hline 28 & & Gliotoxin & GLIO & 5.608 & 18.692 \\
\hline 29 & & Sterigmatocystin & STERIG & 0.184 & 0.612 \\
\hline 30 & & Verruculogen & VER & 0.331 & 1.104 \\
\hline 31 & \multirow[t]{5}{*}{ Ergot Alkaloids } & Ergometrine & ERGOM & 0.573 & 1.911 \\
\hline 32 & & Ergotamine & ERGOTA & 0.502 & 1.673 \\
\hline 33 & & Ergocryptine & ERGOCRP & 0.803 & 2.677 \\
\hline 34 & & Lysergol & LYSERG & 0.457 & 1.522 \\
\hline 35 & & Methylergonovine & MERGON & 0.048 & 0.161 \\
\hline
\end{tabular}

Analysis for the simultaneous presence of the 35 mycotoxins was carried out by the Alltech $37+{ }^{\circledR}$ Analytical Services Laboratory located in Nicholasville, KY, USA (ISO/IEC 
17025:2005 No. 79481, Certificate No. L14-281 and ISO/IEC 17025:2017 official accreditation No. 79481, Certificate No. L20-392, Perry Johnson Laboratory Accreditation, Inc.) following methods published by Jackson et al. [56]. Samples were processed immediately upon receipt. Silage samples were freeze dried for $\geq 36 \mathrm{~h}$ to remove water whereas the moisture content of corn grain was determined immediately. Each sample was then finely ground using an EK43 grinder (Mahlkönig GmbH and Co., Hamburg, Germany). Aliquots (400 mg $\pm 2 \%$ ) of samples were placed in reaction tubes and spiked with $20 \mu \mathrm{L}$ of a 1:1:1 internal standard mixture ( $\left[{ }^{13} \mathrm{C}_{15}\right]$-DON at $4.5 \mu \mathrm{g} / \mathrm{g}$; $\left[{ }^{13} \mathrm{C}_{18}\right]-Z E A$ at $4.5 \mu \mathrm{g} / \mathrm{g}$; $\left[{ }^{13} \mathrm{C}_{17}\right]-A F B 1$ at $\left.273 \mathrm{ng} / \mathrm{g}\right)$. Corn grain samples were extracted with $1600 \mu \mathrm{L}$ and corn silage with $3200 \mu \mathrm{L}$ of a mixture of acetonitrile/water/formic acid (84.0:15.9:0.1, $v / v / v$ ) for $18 \mathrm{~h}$ at room temperature (RT) with shaking (300 rpm, New Brunswick Scientific, Enfield, CT, USA). All samples were centrifuged at 12,000 rpm for 15 min (Beckman Coulter Inc., Fullerton, CA, USA). Supernatant ( $400 \mu \mathrm{L}$ for corn grain; $800 \mu \mathrm{L}$ for corn silage) was collected and added to an autosampler vial and dried under a $\mathrm{N}_{2}$ stream for $30 \mathrm{~min}$ at RT. Samples were reconstituted in $400 \mu \mathrm{L}$ of loading buffer (LB) consisting of water/acetonitrile/formic acid (95.0:4.9:0.1, $v / v / v)$ containing $10 \mathrm{mmol} \mathrm{L}^{-1}$ ammonium acetate. An internal standard solution $(20 \mu \mathrm{L})$ of $\left[{ }^{13} \mathrm{C}_{34}\right]-\mathrm{FB} 1$ at $2.3 \mu \mathrm{g} / \mathrm{g}$ was added to each reconstituted sample before vials were placed in the UPLC autosampler. Salinized glass vials with a dichlorodimethylsilane solution were used throughout the study to prevent mycotoxin interaction with glassware.

Calibration standards were prepared from a stock solution containing a mixture of 35 mycotoxins. The solution was diluted 1:4 $(v / v)$ with acetonitrile five times to yield the following dilutions 1(A):4(B):16(C):64(D):256(E):1024(F). The linear calibration curve spanned concentrations differing by $2-5$ orders of magnitude, depending on the analyte. Blank samples and a certified reference material were used after the calibration curve was built, and a system suitability check using standard solution $C$ was performed after every five injections. The recovered levels of certified mycotoxins were accurate within $\pm 25 \%$.

Ultra-pressure liquid chromatography with tandem mass spectrometry (UPLC-MS/MS) analysis was performed on a Waters Acquity UPLC-TQD system (Waters Corp., Milford, MA, USA) following methods of Jackson et al. [56] and utilizing an ethylene-bridged hybrid (BEH) C18 analytical column (1.7 $\mu \mathrm{m}$ particle size, $2.1 \times 100 \mathrm{~mm}$, Waters Corp., Milford, MA, USA) maintained at $40^{\circ} \mathrm{C}$. Analyses were performed at $0.41 \mathrm{~mL} / \mathrm{min}$ over $16 \mathrm{~min}$ per sample injection with a gradient of water (eluent A) and methanol (eluent B), both containing $0.1 \%(v / v)$ formic acid. The column was held at its initial condition $(5 \% \mathrm{~B})$ for $2 \mathrm{~min}$, followed by a linear increase to $10 \%$ B over $2 \mathrm{~min}$, followed by a linear increase to $75 \%$ B over $8 \mathrm{~min}$, then maintained at $99 \% \mathrm{~B}$ for $2 \mathrm{~min}$, and finally re-equilibrated for $2 \mathrm{~min}$ with $5 \%$ B. Full loop injections of $10 \mu \mathrm{L}$ were performed with $4 \times$ loop overfill without further sample preparation.

The MS was operated under the following conditions: source temperature $\left(150{ }^{\circ} \mathrm{C}\right)$, cone gas flow rate $(20 \mathrm{~L} / \mathrm{h})$, desolvation gas flow rate $(450 \mathrm{~L} / \mathrm{h})$, cone voltage $(20 \mathrm{~V})$, and capillary voltage $(1 \mathrm{kV})$. Nitrogen (purity $99.0 \%$; Nitroflow, Parker-Balston, Haverhill, MA, USA) was used as the desolvation gas and the cone gas. The MS was operated in both negative or positive ion multiple reaction monitoring (MRM) mode for each compound in 1 min segments centered on the retention time of the target analyte, based on $[\mathrm{M}+\mathrm{H}]^{+}$, $\left[\mathrm{M}+\mathrm{NH}_{4}\right]^{+},[\mathrm{M}-\mathrm{H}]^{-}[\mathrm{M}+\text { formate }]^{-}$precursor ion formation. Peak width was estimated at $6 \mathrm{~s}$ and a desired value of 16 points per peak was chosen. The instrument was set to automatic dwell on each transition.

\subsection{Statistical Analysis}

We analyzed mycotoxin concentrations for each of the 10 groups of mycotoxins (described above) for corn and corn silage samples by year using analysis of variance (ANOVA). Mycotoxin concentrations were log transformed to satisfy assumptions of normality. Statistical analyses were performed with $R$ using built-in functions [57].

We characterized the co-occurrence of mycotoxins present among samples by constructing a series of probabilistic models. These models examined pairwise co-occurrences 
of individual mycotoxins following the methods of Veech [58] and Griffith et al. [59]. Measures of co-occurrence were evaluated by the observed number of instances samples contained two individual mycotoxins relative to the expected number of times that these would occur together by random chance. Separate analyses were conducted for corn and corn silage samples and among individual mycotoxins (i.e., two analyses).

Matrices for each analysis were constructed comprising of $0^{\prime} \mathrm{s}$ and $1^{\prime} \mathrm{s}$. Among samples, laboratory analyses that detected a mycotoxin, reported as a positive, non-zero concentration, were assigned a " 1 ", and analyses that did not detect a mycotoxin, reported as a zero, were assigned a " 0 ". We calculated the probability of co-occurrence sensu Griffith et al. [59] that a corn or corn silage sample would contain an individual mycotoxin given that it contained a second individual mycotoxin as,

$$
P j=\frac{\left(\begin{array}{c}
N_{x} \\
j
\end{array}\right) \times\left(\begin{array}{c}
N-N_{x} \\
N_{y}-j
\end{array}\right)}{\left(\begin{array}{c}
N \\
N_{y}
\end{array}\right)},
$$

where $j=1$ to $N x$ samples, $N x$ is the number of samples where mycotoxin $x$ occurs, $N y$ is the number of samples where mycotoxin $y$ occurs, and $N$ is the total number of samples that were analyzed where both $x$ and $y$ mycotoxins could occur. The term $\left(\begin{array}{c}N_{x} \\ j\end{array}\right)$, is the number of ways of selecting $j$ samples that have mycotoxin $x$ given there are $N x$ samples that were analyzed. The term $\left(\begin{array}{c}N-N_{x} \\ N_{y}-j\end{array}\right)$, is the number of ways of selecting $N y-j$ samples that have mycotoxin $y$ but not mycotoxin $x$ given there are $N-N x$ sites. The term $\left(\begin{array}{c}N \\ N_{y}\end{array}\right)$, is the total number of combinations that the number of samples $N y$ could be obtained out of all $N$ samples. A mycotoxin co-occurrence matrix was constructed along with an observed-expected plot to visually evaluate whether probabilities of observed frequencies of co-occurrence were greater than (red), less than (blue), or equivalent (i.e., random) to (grey) expected co-occurrences. This approach to analyzing species co-occurrence was performed in R with the package "cooccur" [59].

Author Contributions: Conceptualization, A.C.W.; methodology, A.C.W.; validation, A.C.W. and A.Y.; formal analysis, D.M.W., Alltech $37+{ }^{\circledR}$ Analytical Laboratory; investigation, A.C.W. and A.Y.; resources, Alltech 37+ Analytical Laboratory; data curation, A.C.W.; writing-original draft preparation, A.C.W.; writing-review and editing, A.C.W., D.M.W., N.A. and A.Y.; visualization, A.C.W. and D.M.W.; supervision, N.A.; project administration, N.A. and A.Y.; funding acquisition, N.A. and A.Y. All authors have read and agreed to the published version of the manuscript.

Funding: This research was financially supported by Alltech, Inc., Nicholasville, KY, USA.

Institutional Review Board Statement: Not applicable.

Informed Consent Statement: Not applicable.

Data Availability Statement: Data will be provided upon request.

Acknowledgments: We thank the members of the Alltech $37+{ }^{\circledR}$ Analytical Laboratory in Nicholasville, KY for analysis of multiple mycotoxins in samples using UPLC-MS/MS. We also appreciate the dedicated Alltech employees for collection of the grain and silage samples we used in this survey.

Conflicts of Interest: The authors declare no conflict of interest. The funders, individuals collecting samples, and individuals performing mycotoxin analysis had no role in the design of the study, the interpretation of data, the writing of the manuscript, or in the decision to publish the results. 


\section{References}

1. Mueller, D.S.; Wise, K.A.; Sisson, A.J.; Allen, T.W.; Bergstrom, G.C.; Bosley, D.B.; Bradley, C.A.; Broders, K.D.; Byamukama, E.; Chilvers, M.I.; et al. Corn yield loss estimates due to diseases in the United States and Ontario, Canada from 2012 to 2015. Plant Health Prog. 2016, 17, 211-222. [CrossRef]

2. Salgado, J.D.; Madden, L.V.; Paul, P.A. Quantifying the effects of Fusarium head blight on grain yield and test weight in soft red winter wheat. Phytopathology 2015, 105, 295-306. [CrossRef]

3. CAST. Mycotoxins: Risks in Plant, Animal, and Human Systems; Task Force Report No. 139; Council for Agricultural Science and Technology: Ames, IA, USA, 2003.

4. Jouany, J.P. Methods for preventing, decontaminating and minimizing the toxicity of mycotoxins in feeds. Anim. Feed Sci. Technol. 2007, 137, 342-362. [CrossRef]

5. Vandicke, J.; De Visschere, K.; Croubels, S.; De Saeger, S.; Audenaert, K.; Haesaert, G. Mycotoxins in Flanders' Fields: Occurrence and Correlations with Fusarium Species in Whole-Plant Harvested Maize. Microorganisms 2019, 7, 571. [CrossRef] [PubMed]

6. Weaver, A.C.; Nicholas Adams, N.; Yiannikouris, A. Use of technology to assess and monitor multi mycotoxin and emerging mycotoxin challenges in feedstuffs. Appl. Anim. Sci. 2020, 36, 19-25. [CrossRef]

7. Kolawole, O.; Graham, A.; Donaldson, C.; Owens, B.; Abia, W.A.; Meneely, J.; Alcorn, M.J.; Connolly, L.; Elliott, C.T. Low Doses of Mycotoxin Mixtures below EU Regulatory Limits Can Negatively Affect the Performance of Broiler Chickens: A Longitudinal Study. Toxins 2020, 12, 433. [CrossRef] [PubMed]

8. NGFA 2019 National Grain and Feed Association. FDA mycotoxin regulatory guidance. In A Guide for Grain Elevators, Feed Manufacturers, Grain Processors and Exporter; National Grain and Feed Association: Arlington, VA, USA, 2019.

9. Pulina, G.; Battacone, G.; Brambilla, G.; Cheli, F.; Danieli, P.P.; Masoero, F.; Pietri, A.; Ronchi, B. An update on the safety of foods of animal origin and feeds. Ital. J. Anim. Sci. 2014, 13, 845-856. [CrossRef]

10. Devreese, M.; De Backer, P.; Croubels, S. Overview of the most important mycotoxins for the pig and poultry husbandry. Vlaams Diergeneeskd. Tijdschr. 2013, 82, 171-180. [CrossRef]

11. Fink-Gremmels, J. The role of mycotoxins in the health and performance of dairy cows. Vet. J. 2008, 176, 84-92. [CrossRef]

12. Jia, R.; Liu, W.; Zhao, L.; Cao, L.; Shen, Z. Low doses of individual and combined deoxynivalenol and zearalenone in naturally moldy diets impair intestinal functions via inducing inflammation and disrupting epithelial barrier in the intestine of piglets. Toxicol. Lett. 2020, 333, 159-169. [CrossRef] [PubMed]

13. Andretta, I.; Kipper, M.; Hauschild, L.; Lehnen, C.R.; Remus, A.; Melchior, R. Meta-analysis of individual and combined effects of mycotoxins on growing pigs. Sci. Agric. 2016, 73, 328-331. [CrossRef]

14. Kipper, M.; Andretta, I.; Ribeiro, A.M.L.; da Silva Pires, P.G.; Franceschina, C.S.; Cardinal, K.M.; de Oliveira Moraes, P.; Schroeder, B. Assessing the implications of mycotoxins on productive efficiency of broilers and growing pigs. Sci. Agric. 2020, 77, e20180236. [CrossRef]

15. Reisinger, N.; Schürer-Waldheim, S.; Mayer, E.; Debevere, S.; Antonissen, G.; Sulyok, M.; Nagl, V. Mycotoxin Occurrence in Maize Silage-A Neglected Risk for Bovine Gut Health? Toxins 2019, 11, 577. [CrossRef] [PubMed]

16. Bacon, C.W.; Porter, J.K.; Norred, W.P.; Leslie, J.F. Production of Fusaric Acid by Fusarium Species. Appl. Environ. Microbiol. 1996, 62, 4039-4043. [CrossRef] [PubMed]

17. Smith, T.K.; McMillan, E.G.; Castillo, J.B. Effects of feeding blends of Fusarium mycotoxin-contaminated grains containing deoxynivalenol and fusaric acid on growth and feed consumption of immature swine. J. Anim. Sci. 1997, 75, 2184-2191. [CrossRef]

18. Parmar, P.; Oza, V.P.; Subramanian, R.B. Optimization of fusaric acid production by Fusarium oxysporum f. sp. lycopersici using response surface methodology. Indian J. Sci. Technol. 2010, 3, 411-416. [CrossRef]

19. Ogunbo, S.O.; Broomhead, J.N.; Ledoux, D.R.; Bermudez, A.J.; Rottinghaus, G.E. The individual and combined effects of fusaric acid and T-2 toxin in broilers and turkeys. Internat. J. Poult. Sci. 2007, 6, 484-488. [CrossRef]

20. Park, J.; Kim, D.-H.; Moon, J.-Y.; An, J.-A.; Kim, Y.-W.; Chung, S.-H.; Lee, C. Distribution Analysis of Twelve Mycotoxins in Corn and Corn-Derived Products by LC-MS/MS to Evaluate the Carry-Over Ratio during Wet-Milling. Toxins 2018, 10, 319. [CrossRef] [PubMed]

21. Birr, T.; Jensen, T.; Preußke, N.; Sönnichsen, F.D.; De Boevre, M.; De Saeger, S.; Hasler, M.; Verreet, J.-A.; Klink, H. Occurrence of Fusarium Mycotoxins and Their Modified Forms in Forage Maize Cultivars. Toxins 2021, 13, 110. [CrossRef]

22. Alizadeh, A.; Braber, S.; Akbari, P.; Garssen, J.; Fink-Gremmels, J. Deoxynivalenol Impairs Weight Gain and Affects Markers of Gut Health after Low-Dose, Short-Term Exposure of Growing Pigs. Toxins 2015, 7, 2071-2095. [CrossRef]

23. Holanda, D.M.; Kim, S.W. Mycotoxin Occurrence, Toxicity, and Detoxifying Agents in Pig Production with an Emphasis on Deoxynivalenol. Toxins 2021, 13, 171. [CrossRef]

24. House, J.D.; Abramson, D.; Crow, G.H.; Nyachoti, C.M. Feed intake, growth and carcass parameters of swine consuming diets containing low levels of deoxynivalenol from naturally contaminated barley. Can. J. Anim. Sci. 2002, 82, 559-565. [CrossRef]

25. Weaver, A.C.; King, W.D.; Verax, M.; Fox, U.; Kudupoje, M.B.; Mathis, G.; Lumpkins, B.; Yiannikouris, A. Impact of Chronic Levels of Naturally Multi-Contaminated Feed with Fusarium Mycotoxins on Broiler Chickens and Evaluation of the Mitigation Properties of Different Titers of Yeast Cell Wall Extract. Toxins 2020, 12, 636. [CrossRef] [PubMed]

26. Tazerout, N. Détermination des concentrations de déoxynivalénol et zéaralénone associées à des maladies chez les vaches Laitières. In Master of Science; University of Montreal: Montreal, QC, Canada, 2016. 
27. Nelson, P.E.; Desjardins, A.E.; Plattner, R.D. Fumonisins, mycotoxins produced by Fusarium species: Biology, chemistry, and significance. Annu. Rev. Phytopathol. 1993, 31, 233-252. [CrossRef] [PubMed]

28. Oswald, I.P.; Desautels, C.; Laffitte, J.; Fournout, S.; Peres, S.Y.; Odin, M.; Le Bars, P.; Le Bars, J.; Fairbrother, J.M. Mycotoxin Fumonisin B1 Increases Intestinal Colonization by Pathogenic Escherichia coli in Pigs. Appl. Environ. Microbiol. 2003, 69, 5870-5874. [CrossRef] [PubMed]

29. Wu, F.; Cui, J.; Yang, X.; Liu, S.; Han, S.; Chen, B. Effects of zearalenone on genital organ development, serum immunoglobulin, antioxidant capacity, sex hormones and liver function of prepubertal gilts. Toxicon 2021, 189, 39-44. [CrossRef]

30. Wu, F. Global impacts of aflatoxin in maize: Trade and human health. World Mycotoxin J. 2015, 8, 137-142. [CrossRef]

31. Cheli, F.; Campagnoli, A.; Pinotti, L.; Fusi, E.; Dell’Orto, V. Sampling feed for mycotoxins: Acquiring knowledge from food. Ital. J. Anim. Sci. 2009, 8, 5-22. [CrossRef]

32. Cheli, F.; Campagnoli, A.; Dell'Orto, V. Fungal populations and mycotoxins in silages: From occurrence to analysis. Anim. Feed Sci. Technol. 2013, 183, 1-16. [CrossRef]

33. Schiff, P.L. Ergot and Its Alkaloids. Am. J. Pharm. Educ. 2006, 70, 98. [CrossRef]

34. Bragg, P.E.; Maust, M.D.; Panaccione, D.G. Ergot Alkaloid Biosynthesis in the Maize (Zea mays) Ergot Fungus Claviceps gigantea. J. Agric. Food Chem. 2017, 65, 10703-10710. [CrossRef] [PubMed]

35. Naudè, T.W.; Botha, C.J.; Vorster, J.H.; Roux, C.; Van Der Linde, E.J.; Van Der Walt, S.I.; Rottinghaus, G.E.; Van Jaarsveld, L.; Lawrence, A.N. Claviceps cyperi, a new cause of severe ergotism in dairy cattle consuming maize silage and teff hay contaminated with ergotised Cyperus esculentus (nut sedge) on the Highveld of South Africa. Onderstepoort J. Vet. Res. 2005, $72,23-37$. [CrossRef] [PubMed]

36. Patton, A.; Welsenberger, D. Yellow Nutsedge Control; Perdue Extension: West Lafayette, IN, USA, 2013; publication AY-19-W.

37. Oh, S.-Y.; Boermans, H.J.; Swamy, H.V.L.N.; Sharma, B.S.; Karrow, N.A. Immunotoxicity of Penicillium Mycotoxins on Viability and Proliferation of Bovine Macrophage Cell Line (BOMACs). Open Mycol. J. 2012, 6, 11-16. [CrossRef]

38. Alassane-Kpembi, I.; Kolf-Clauw, M.; Gauthier, T.; Abrami, R.; Abiola, F.A.; Oswald, I.P.; Puel, O. New insights into mycotoxin mixtures: The toxicity of low doses of Type B Trichothecenes on intestinal epithelial cells is synergistic. Toxicol. Appl. Pharmacol. 2013, 272, 191-198. [CrossRef]

39. Wan, L.Y.M.; Turner, P.C.; El-Nezami, H. Individual and combined cytotoxic effects of Fusarium toxins (deoxynivalenol, nivalenol, zearalenone and fumonisins B1) on swine jejunal epithelial cells. Food Chem. Toxicol. 2013, 57, 276-283. [CrossRef]

40. Gerez, J.R.; Pinton, P.; Callu, P.; Grosjean, F.; Oswald, I.P.; Bracarense, A.P.F.L. Deoxynivalenol alone or in combination with nivalenol and zearalenone induce systemic histological changes in pigs. Exp. Toxicol. Pathol. 2014, 67, 89-98. [CrossRef]

41. Shen, Y.-B.; Weaver, A.C.; Kim, S.W. Physiological effects of deoxynivalenol from naturally contaminated corn on cerebral tryptophan metabolism, behavioral response, gastrointestinal immune status and health of pigs following a pair-feeding model. Toxins 2021, 13, 393. [CrossRef]

42. Smith, T.K.; Sousadias, M.G. Fusaric acid content of swine feedstuffs. J. Agric. Food Chem. 1993, 41, 2296-2298. [CrossRef]

43. Grenier, B.; Loureiro-Bracarense, A.-P.; Lucioli, J.; Pacheco, G.D.; Cossalter, A.-M.; Moll, W.-D.; Schatzmayr, G.; Oswald, I.P. Individual and combined effects of subclinical doses of deoxynivalenol and fumonisins in piglets. Mol. Nutr. Food Res. 2011, 55, 761-771. [CrossRef] [PubMed]

44. Liu, J.D.; Doupovec, B.; Schatzmayr, D.; Murugesan, G.R.; Bortoluzzi, C.; Villegas, A.M.; Applegate, T.J. The impact of deoxynivalenol, fumonisins, and their combination on performance, nutrient, and energy digestibility in broiler chickens. Poult. Sci. 2020, 99, 272-279. [CrossRef] [PubMed]

45. Maresca, M. From the gut to the brain: Journey and pathophysiological effects of the food-associated trichothecene mycotoxin deoxynivalenol. Toxins 2013, 5, 784-830. [CrossRef]

46. Pinton, P.; Tsybulskyy, D.; Lucioli, J.; Laffitte, J.; Callu, P.; Lyazhri, F.; Grosjean, F.; Bracarense, A.P.; Kolf-Clauw, M.; Oswald, I.P. Toxicity of Deoxynivalenol and Its Acetylated Derivatives on the Intestine: Differential Effects on Morphology, Barrier Function, Tight Junction Proteins, and Mitogen-Activated Protein Kinases. Toxicol. Sci. 2012, 130, 180-190. [CrossRef] [PubMed]

47. Vandicke, J.; De Visschere, K.; Ameye, M.; Croubels, S.; De Saeger, S.; Audenaert, K.; Haesaert, G. Multi-Mycotoxin Contamination of Maize Silages in Flanders, Belgium: Monitoring Mycotoxin Levels from Seed to Feed. Toxins 2021, 13, 202. [CrossRef] [PubMed]

48. Pitt, J.I.; Taniwaki, M.H.; Cole, M.B. Mycotoxin production in major crops as influenced by growing, harvesting, storage and processing, with emphasis on the achievement of Food Safety Objectives. Food Control 2013, 32, 205-215. [CrossRef]

49. National Oceanic and Atmospheric Administration (NOAA). Climate at a Glance: National Time Series; National Centers for Environmental Information: Asheville, NC, USA, 2021. Available online: https://www.ncdc.noaa.gov/cag/ (accessed on 20 May 2021).

50. Mueller, D.S.; Wise, K.A.; Sisson, A.J.; Allen, T.W.; Bergstrom, G.C.; Bissonnette, K.M.; Bradley, C.A.; Byamukama, E.; Chilvers, M.I.; Collins, A.A.; et al. Corn yield loss estimates due to diseases in the United States and Ontario, Canada, from 2016 to 2019. Plant Health Prog. 2020, 21, 238-247. [CrossRef]

51. Ji, F.; Wu, J.; Zhao, H.; Xu, J.; Shi, J. Relationship of Deoxynivalenol Content in Grain, Chaff, and Straw with Fusarium Head Blight Severity in Wheat Varieties with Various Levels of Resistance. Toxins 2015, 7, 728-742. [CrossRef]

52. Di Menna, M.E.; Lauren, D.R.; Hardacre, A. Fusarium and Fusarium toxins in New Zealand maize plants. Mycopathologia 1997, 139, 165-173. [CrossRef] 
53. Scauflaire, J.; Mahieu, O.; Louvieaux, J.; Foucart, G.; Renard, F.; Munaut, F. Biodiversity of Fusarium species in ears and stalks of maize plants in Belgium. Eur. J. Plant Pathol. 2011, 131, 59-66. [CrossRef]

54. USDA-GIPSA. Grain Inspection Handbook, Book 1 Sampling; United States Department of Agriculture: Washington, DC, USA, 2013.

55. Undersander, D.; Shaver, R.; Linn, J.; Hoffman, P.; Peterson, P. Sampling Hay, Silage and Total Mixed Rations for Analysis; University of Wisconsin Extension: Madison, WI, USA, 2005.

56. Jackson, L.C.; Kudupoje, M.B.; Yiannikouris, A. Simultaneous multiple mycotoxin quantification in feed samples using three isotopically labeled internal standards applied for isotopic dilution and data normalization through ultra-performance liquid chromatography/electrospray ionization tandem mass spectrometry. Rapid Commun. Mass Spectrom. 2012, 26, $2697-2713$. [CrossRef]

57. RStudio Team. RStudio: Integrated Development for R. RStudio; PBC: Boston, MA, USA, 2020; Version 1.1.463; Available online: http:/ / www.rstudio.com/ (accessed on 1 July 2020).

58. Veech, J.A. A probabilistic model for analyzing species co-occurrence. Glob. Ecol. Biogeogr. 2013, 22, 252-260. [CrossRef]

59. Griffith, D.M.; Veech, J.A.; Marsh, C.J. Cooccur: Probabilistic species co-occurrence analysis in R. J. Stat. Softw. 2016, 69, 1-17. [CrossRef] 